\title{
Article \\ Membrane Sterol Composition in Arabidopsis thaliana Affects Root Elongation via Auxin Biosynthesis
}

\author{
Meng Wang ${ }^{1}$, Panpan $\mathrm{Li}^{1}{ }^{1}$, Yao Ma ${ }^{1}$, Xiang Nie ${ }^{1}$, Markus Grebe ${ }^{2}$ and Shuzhen Men ${ }^{1, *(1)}$ \\ 1 Department of Plant Biology and Ecology, College of Life Sciences, Nankai University and Tianjin Key \\ Laboratory of Protein Sciences, Tianjin 300071, China; wangmm113@126.com (M.W.); \\ panda411190351@126.com (P.L.); yaoma@mail.nankai.edu.cn (Y.M.); niexiang@nankai.edu.cn (X.N.) \\ 2 Institute of Biochemistry and Biology, Plant Physiology, University of Potsdam, \\ D-14476 Potsdam-Golm, Germany; markus.grebe@uni-potsdam.de \\ * Correspondence: shuzhenmen@nankai.edu.cn
}

Citation: Wang, M.; Li, P.; Ma, Y.; Nie, X.; Grebe, M.; Men, S. Membrane Sterol Composition in Arabidopsis thaliana Affects Root Elongation via Auxin Biosynthesis. Int. J. Mol. Sci. 2021, 22, 437. https://doi.org/ 10.3390/ijms22010437

Received: 15 December 2020 Accepted: 30 December 2020 Published: 4 January 2021

Publisher's Note: MDPI stays neutral with regard to jurisdictional clai$\mathrm{ms}$ in published maps and institutional affiliations.

Copyright: (C) 2021 by the authors. Licensee MDPI, Basel, Switzerland. This article is an open access article distributed under the terms and conditions of the Creative Commons Attribution (CC BY) license (https:// creativecommons.org/licenses/by/ $4.0 /)$.

\begin{abstract}
Plant membrane sterol composition has been reported to affect growth and gravitropism via polar auxin transport and auxin signaling. However, as to whether sterols influence auxin biosynthesis has received little attention. Here, by using the sterol biosynthesis mutant cyclopropylsterol isomerase1-1 (cpi1-1) and sterol application, we reveal that cycloeucalenol, a CPI1 substrate, and sitosterol, an end-product of sterol biosynthesis, antagonistically affect auxin biosynthesis. The short root phenotype of cpi1-1 was associated with a markedly enhanced auxin response in the root tip. Both were neither suppressed by mutations in polar auxin transport (PAT) proteins nor by treatment with a PAT inhibitor and responded to an auxin signaling inhibitor. However, expression of several auxin biosynthesis genes TRYPTOPHAN AMINOTRANSFERASE OF ARABIDOPSIS1 (TAA1) was upregulated in cpi1-1. Functionally, TAA1 mutation reduced the auxin response in cpi1-1 and partially rescued its short root phenotype. In support of this genetic evidence, application of cycloeucalenol upregulated expression of the auxin responsive reporter DR5:GUS ( $\beta$-glucuronidase) and of several auxin biosynthesis genes, while sitosterol repressed their expression. Hence, our combined genetic, pharmacological, and sterol application studies reveal a hitherto unexplored sterol-dependent modulation of auxin biosynthesis during Arabidopsis root elongation.
\end{abstract}

Keywords: Arabidopsis thaliana; auxin; auxin biosynthesis; cycloeucalenol; CPI1; sitosterol; sterol

\section{Introduction}

Sterols are essential membrane components in all eukaryotes [1]. Plants have a complex sterol composition in which sitosterol, campesterol, stigmasterol, and isofucosterol are predominant [2-5]. Besides, sterol biosynthetic intermediates (SBIs), such as cycloartenol, 24-methylene cycloartanol, cycloeucalenol, obtusifoliol, 24-ethylidene lophenol, are present as minor sterol compounds [2,6-10] (Supplemental Figure S1). Campesterol is the precursor for the biosynthesis of brassinosteroids (BRs), which is the only steroid hormone identified in plants so far. Whereas the dwarf phenotype of downstream sterol biosynthesis mutants, such as dwarf7 (dwf7)/sterol1 (ste1), dwf5, and dwf1/diminuto (dim) could be rescued by BRs [11-14], the defect of root or hypocotyl elongation in upstream mutants such as fackel (fk)/hydra2 (hyd2), hyd1, sterol methyltransferase1 (smt1), cyp51A2, cyclopropylsterol isomerase1-1 (cpi1-1), sterol $4 \alpha$-methyl oxidase2-1 (smo2-1) smo2-2/+, and smo1-1 smo1-2/+ could not be rescued by BRs [8,15-22], suggesting essential roles of sterols per se in cell division and cell expansion.

The upstream sterol mutants often display defects in auxin response and polar auxin transport (PAT). The $f k / h y d 2$ and $h y d 1$ mutants showed enhanced responses to auxin, and their short root and short leaf petiole phenotypes could be partially rescued by blocking auxin signaling [23]. The cotyledon vascular patterning1 (cop1) mutant showed weak auxin insensitivity, and could enhance the auxin resistance of transport inhibitor resistant 1 
(tir1) and auxin resistance1-3 (axr1-3) mutants [9,24]. The smt1, cpi1-1, fk/hyd2, hyd1, smt2 smt3, smo2-1 smo2-2, and smo1-1 smo1-2 mutants displayed aberrant localizations of PINFORMED (PIN) auxin efflux carriers in seedling root or embryo [8,19,21,22,25-27]. It has been demonstrated that sterol endocytosis shares a common route with PIN2 recycling [28], and correct sterol composition was required for endocytosis of PIN2 for the establishment of its polar localization after cytokinesis [8]. Recycling of PIN2 from brefeldin A (BFA) toxin-induced endocytic agglomerates to the plasma membrane was inhibited in the smt2 smt3 mutant [26]. Sterols were also required for auxin inhibition of PIN2 endocytosis [24]. Zhang et al. (2016) demonstrated that the embryo-lethal phenotype of the smo2-1 smo2-2 double mutant could be partially rescued by endogenous or exogenous auxin supplementation, while the dwarf phenotype of the smo2-1 smo2-2/+ mutant was completely rescued by endogenous auxin overproduction [21]. This finding implies that not only PAT was defective in sterol mutants, but auxin biosynthesis might be abnormal as well. Indeed, recently Song et al. (2019) showed that in the smo1-1 smo1-2 embryos, expression of the TRYPTOPHAN AMINOTRANSFERASE OF ARABIDOPSIS1 (TAA1) and YUCCA9 (YUC9) auxin biosynthesis pathway genes was abnormal [22]. However, how sterols modulate auxin biosynthesis remains unclear.

In this study, we used the cpi1-1 mutant to dissect the function of sterols in modulating auxin biosynthesis. The CPI1 gene encodes the cyclopropylsterol isomerase, which is responsible for opening the $9 \beta, 19$-cyclopropane ring of cycloeucalenol and converting it into obtusifoliol $[29,30]$ (Supplemental Figure S1B). The cpi1-1 mutant exhibits a short root, agravitropism, and stomatal developmental defects [8,31]. Expression of the auxin responsive reporter DR5:GUS [32,33] in the cpi1-1 root tip was markedly enhanced and expanded to the lateral root cap and epidermal cells [8]. We found that expression of auxin biosynthesis genes including TAA1, YUC8, and YUC9 was upregulated in cpi1-1. TAA1 mutation reduced DR5:GUS expression in cpi1-1 root tip and partially rescued the short root phenotype of cpi1-1. Since sterol composition in cpi1-1 was markedly altered, with accumulation of cycloeucalenol at the expense of almost complete reduction of the major sterols such as sitosterol, 24-methylcholesterol (campesterol), and stigmasterol [8], we analyzed the effect of these sterols on the expression of DR5:GUS and auxin biosynthetic genes and on the root length of wild type (WT) and cpi1-1. We found that cycloeucalenol upregulated the expression of DR5:GUS and auxin biosynthetic genes, whereas sitosterol repressed the expression of these genes and partially rescued the short root phenotype of cpi1-1.

\section{Results}

2.1. An Increased Auxin Response in cpi1-1 is Further Enhanced by Defective Polar Auxin Transport

We initially observed the auxin response reporter DR5:GUS whose expression correlates with auxin levels $[32,33]$. Compared to the WT, cpi1-1 displayed markedly enhanced and ectopic DR5:GUS expression (Figure 1A,B) [8]. In WT cotyledons, DR5:GUS expression was detected at the tip, whereas in cpi1-1, DR5:GUS expression was expanded to the whole cotyledon where the cotyledon tips and the vasculature revealed strong GUS signals (Figure 1A). In the WT root tip, DR5:GUS expression was detected in the stem cell niche and columella root cap cells, whereas in the cpi1-1 root tip, DR5:GUS expression was markedly enhanced and expanded to the lateral root cap and epidermal cells (Figure 1B). In addition, roots of 2-week-old cpi1-1 seedlings displayed more lateral root primordia (which were marked by strong DR5:GUS signal) and lateral roots than that of the WT (Supplemental Figure S2). Polar localization of PIN2 has previously been reported to be defective in cpi1-1 root epidermal and cortex cells [8]. To address whether elevated auxin activity in cpi1-1 was caused by defective PAT, we crossed the loss-of-function pin2-T [8], aux1-T [34], and aux1-T pin2-T [35,36] alleles to cpi1-1, and compared the DR5:GUS expression patterns among the single, double, and triple mutants. The cpi1-1 pin2- $T$ double mutant displayed higher DR5:GUS activity than either cpi1-1 or pin2-T, whereas there was no obvious difference of DR5:GUS activity between cpi1-1 aux1-T and cpi1-1 (Figure 1A-C). 
Similar to the cpi1-1 pin2-T double mutant, the cpi1-1 aux1-T pin2-T triple mutant displayed stronger DR5:GUS activity than either cpi1-1 or aux1-T pin2-T (Figure 1A-C). However, there was no significant difference of the root length between cpi1-1 single, cpi1-1 pin2-T and cpi1-1 aux1-T double, and cpi1-1 aux1-T pin2-T triple mutants (Figure 1D,E). These results indicate that CPI1 and PIN2 mutation have additive effects in DR5:GUS activity in the root tip, but there is not an additive effect on root elongation.

A

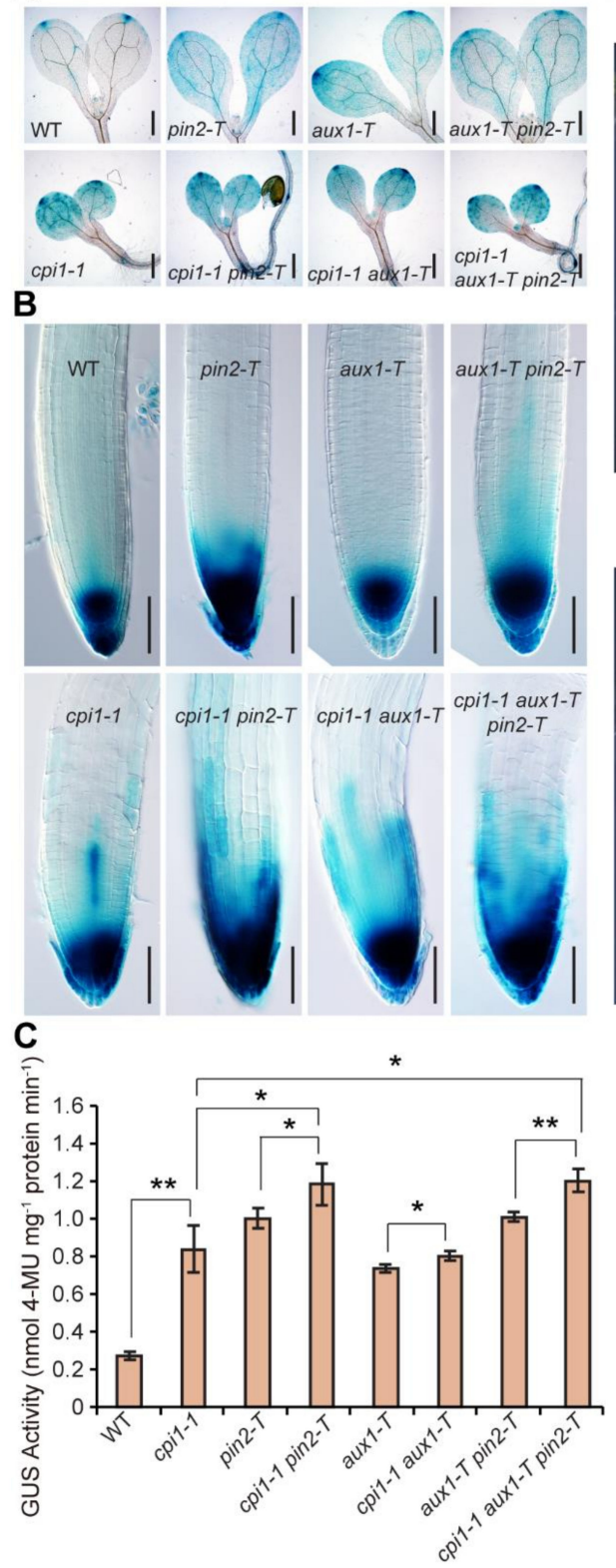

D
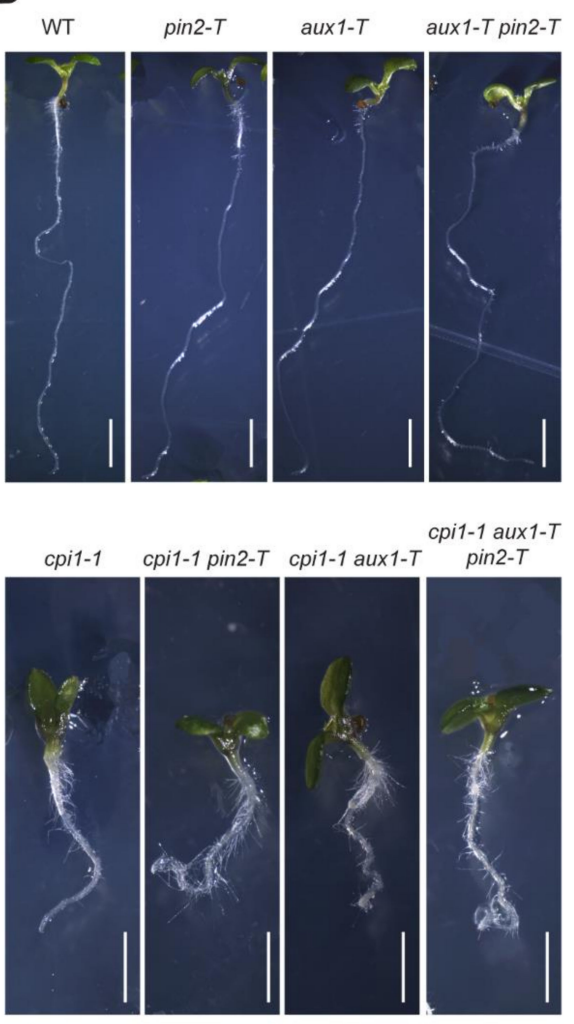

E

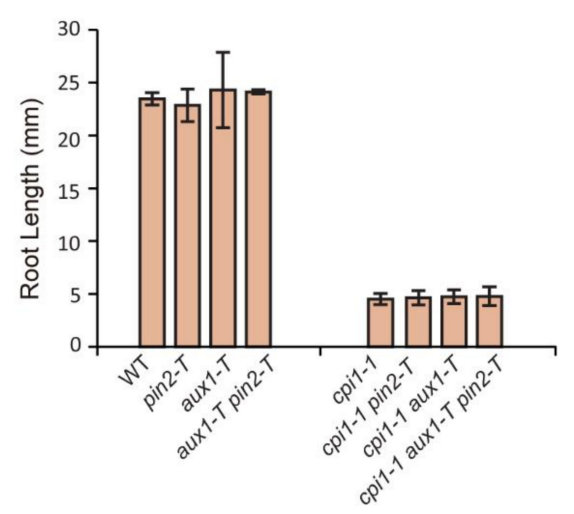

Figure 1. Auxin response reporter expression in and genetic interactions between cpi1-1, pin2-T, and aux1-T mutant combinations. (A,B) DR5:GUS expression patterns in 5-day-old WT, cpi1-1, pin2-T, cpi1-1 pin2-T, aux1-T, cpi1-1 aux1-T, aux1-T pin2-T, and cpi1-1 aux1-T pin2-T cotyledons (A) and seedling roots (B). Shown are representative images of three independent experiments (employing 10 to 16 seedlings per experiment); (C) Quantitative DR5:GUS activity assay in 5-day-old seedlings. The presented data are means $\pm \mathrm{SD}$ of $n=3$ independent experiments. ${ }^{*} p<0.05,{ }^{* *} p<0.01$ (one-way ANOVA with Tukey's test); (D,E) Phenotypes (D) and root length (E) of 7-day-old seedlings. The presented data are means $\pm \mathrm{SD}$ of $n=3$ independent experiments (employing 9 to 37 seedlings per experiment). No significant difference between cpi1-1 single and cpi1-1 pin2-T and cpi1-1 aux1-T double and cpi1-1 aux1-T pin2-T triple mutants by Student's $t$-test (one-tailed, two-sample equal variance, $p<0.05)$. Bars $=400 \mu \mathrm{m}$ in $(\mathbf{A}), 100 \mu \mathrm{m}$ in $(\mathbf{B})$, and $2 \mathrm{~mm}$ in (D). 
Previously Men et al. (2008) had shown that PIN2 transcript level was not affected in cpi1-1 by using semi-quantitative reverse transcription PCR (RT-PCR) [8]. We checked the expression of other PIN genes in cpi1-1 by crossing ProPIN1:GUS, ProPIN3:GUS, ProPIN4:GUS, and ProPIN7:GUS to cpi1-1. Compared to WT, slightly enhanced ProPIN1:GUS and ProPIN3:GUS staining were observed in cpi1-1 (Supplemental Figure S3), while expression of ProPIN4:GUS and ProPIN7:GUS was not obviously different (Supplemental Figure S4A-D). We also examined PIN7 expression by observing ProPIN7:PIN7-GFP (PIN7GFP) fluorescence in seedling root tips. Consistently, no obvious differential expression of PIN7-GFP was detected between cpi1-1 and WT (Supplemental Figure S4E-J). To gain further evidence, RT-quantitative PCR (RT-qPCR) was performed on 7-day-old WT and cpi1-1 seedlings. Consistent with the GUS staining results, relative transcript levels of PIN1 and PIN3 were increased in cpi1-1 mutants (Supplemental Figure S4K).

We further checked the effect of auxin transport inhibitor 1-N-naphthylphthalamic acid (NPA) on DR5:GUS activity in WT and cpi1-1 roots. Compared to the mock, obviously enhanced GUS staining was observed in both WT and cpi1-1 root tips after NPA treatment (Figure 2A). Quantitative GUS activity assays showed that after NPA treatment, DR5:GUS activity was significantly increased in both WT and cpi1-1 seedlings (Figure 2B), but cpi1-1 mutant displayed lower fold induction compared with WT (Figure 2C), suggesting that it is less sensitive to NPA. This result is consistent with the previous report that cpi11 displayed defective polar localization of the PIN2 auxin efflux protein [8]. Whereas higher concentrations of NPA $(500 \mathrm{nM})$ inhibited root elongation of both WT and cpi1-1 seedlings, there was no significant difference in relative root length between WT and cpi1-1 (Figure 2D,E).

A

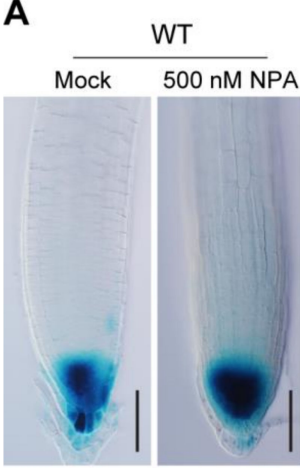

D

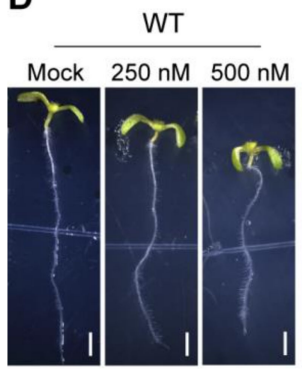

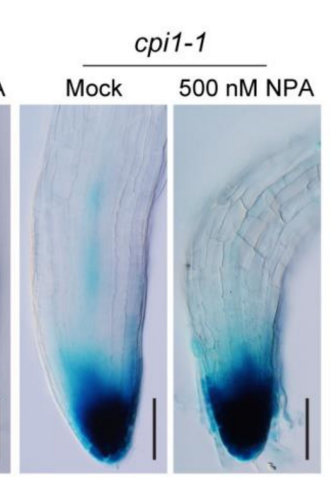

cpi1-1

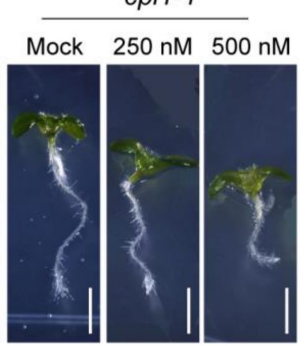

B

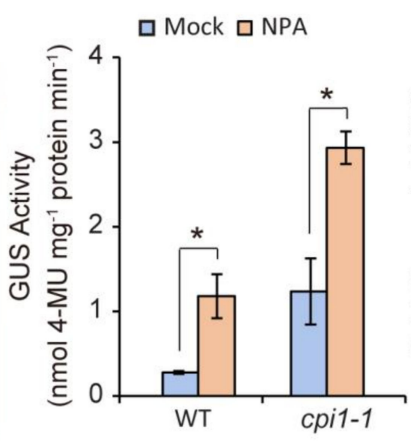

E

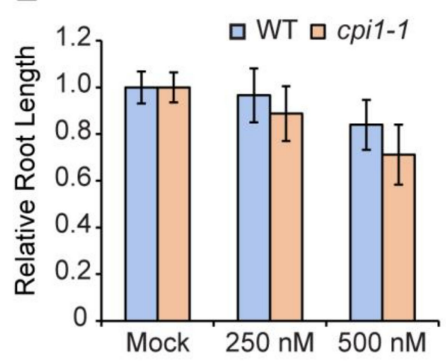

C

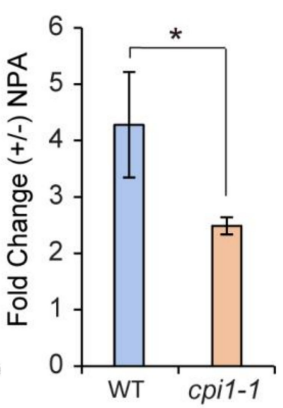

Figure 2. The auxin transport inhibitor 1-N-naphthylphthalamic acid (NPA) increases the DR5:GUS signal in WT and cpi1-1 root tips. (A) NPA increases the DR5:GUS signal in 5-day-old WT and cpi1-1 seedling root tips. Shown are representative images of $n=3$ independent experiments, employing 7 to 21 seedlings per experiment; (B) Quantitative GUS activity assay in 5-day-old WT and cpi1-1 seedlings expressing DR5:GUS; (C) Fold change of DR5:GUS activity in WT and cpi1-1 seedlings upon NPA treatment. The data presented in $(\mathbf{B}, \mathbf{C})$ are means $\pm \mathrm{SD}$ of $n=3$ independent experiments. * $p<0.05$ (Student's $t$-test, one-tailed, two-sample equal variance); (D,E) Phenotypes (D) and relative root length (E) of WT and cpi1-1 seedlings after NPA treatment for 7 days. The data presented in (E) are means \pm SD of $n=3$ independent experiments (employing 10 to 45 seedlings per experiment). No significant difference between WT and cpi1-1 mutant by Student's $t$-test (one-tailed, two-sample equal variance, $p<0.05)$. Bars $=100 \mu \mathrm{m}$ in $(\mathbf{A})$ and $2 \mathrm{~mm}$ in (D). 
Together, these results suggest that other factors in addition to defective PAT contribute to the elevated auxin activity in cpi1-1.

\subsection{The Expression of Auxin Biosynthesis Genes is Upregulated in cpi1-1}

Since auxin biosynthesis and transport contribute to maintain appropriate auxin levels during plant development [37], we analyzed the expression patterns of auxin biosynthesis genes in cpi1-1. The TAA1 (also known as TRANSPORT INHIBITOR RESPONSE2, TIR2 or WEAK ETHYLENE INSENSITIVE8, WEI8) gene encodes tryptophan aminotransferase, which catalyzes the tryptophan (Trp) to indole-3-pyruvic acid (IPA) conversion [38-40]. In order to analyze TAA1 expression patterns in cpi1-1, we crossed ProTIR2:GUS and ProTIR2:TIR2-GUS (a fusion of TAA1/TIR2 cDNA sequence with the GUS reporter gene under control of the TAA1/TIR2 promoter, which rescued the phenotype of the tir 2 mutant) [40] to cpi1-1. In 5-day-old WT seedlings, ProTIR2:GUS signal was detected in cotyledons, hypocotyl, and the root vascular tissue (Supplemental Figure S5A,B; Figure 3A). Compared to WT, obviously increased ProTIR2:GUS expression was observed in cpi1-1 (Supplemental Figure S5C,D; Figure 3B). ProTIR2:TIR2-GUS expression was detected in cotyledons, hypocotyl, root vasculature, and root proximal meristem (Supplemental Figure S5E,F; Figure 3C). Consistent with the results of ProTIR2:GUS, ProTIR2:TIR2-GUS expression was also upregulated in cpi1-1 (Supplemental Figure S5G,H; Figure 3D). In addition, the expression pattern of ProTIR2:TIR2-GUS was altered in the root tip of cpi1-1; it was not detected in the root proximal meristem, but was strongly expressed in the epidermal cells of the root elongation zone (Figure 3D). Since the TAA1/TIR2 cDNA and genomic constructs displayed different expression patterns in the root tip $[38,40,41]$, we also analyzed the expression pattern of ProTAA1:GFP-TAA1 (a fusion of TAA1 genomic sequence with the GFP reporter gene) [38] in cpi1-1. ProTAA1:GFP-TAA1 was strongly expressed in the quiescent center (QC) cells and in columella initials, and its expression was not different between WT and cpi1-1 (Supplemental Figure S6). Together, these results indicate that CPI1 mutation leads to enhanced expression of TAA1 in root vascular tissue and elongation zone, but do not affect its expression in the QC cells. These results are consistent with the previous report that cpi1-1 roots have normal sized meristem but a shorter elongation zone [8].

YUC flavin monooxygenase proteins catalyze the conversion of indole-3-pyruvic acid to indole-3-acetic acid (IAA), which may be considered the rate-limiting step of the main auxin biosynthesis pathway [42-44]. To investigate whether the expression levels of YUC genes were altered in cpi1-1, we crossed ProYUC2:GUS, ProYUC3:GUS, ProYUC4:GUS, ProYUC8:GUS, and ProYUC9:GUS to cpi1-1 [45,46]. In 5-day-old WT seedlings, ProYUC2:GUS was mainly expressed in cotyledons, the vascular tissue in the hypocotyl, in the shoot apical meristem, and in leaf primordia (Supplemental Figure S7A,B). Compared to WT, an enhanced expression of ProYUC2:GUS was observed in cpi1-1 (Supplemental Figure S7C,D). ProYUC3:GUS was mainly expressed in the columella root cap cells, and its expression displayed no obvious difference between WT and cpi1-1 (Supplemental Figure S7E,F). ProYUC4:GUS expression was detected in the tips of the cotyledons, in leaf primordia, and in emerging young leaves, and its expression displayed no obvious difference between WT and cpi1-1 (Supplemental Figure S7G-J). In 5-day-old WT seedlings, ProYUC8:GUS expression was detected mainly in the QC cells and in the columella root cap cells (Figure 3E; Supplemental Figure S8A-C). Of interest, the Pro YUC8:GUS signals in the columella initials as well as in the L1 and L2 layers of the columella root cap cells was lower than that in the QC cells and in the L3 and L4 layers of the columella root cap cells (Supplemental Figure S8C). Compared to WT, increased staining of ProYUC8:GUS was observed in the root vascular tissues of cpi1-1 (Figure 3F; Supplemental Figure S8E), but not in its root QC cells and columella root cap cells (Figure 3F; Supplemental Figure S8F). In 5-day-old WT seedlings, expression of ProYUC9:GUS was observed mainly in the columella root cap cells, in the root tip elongation zone, as well as in the root vasculature (Figure 3G; Supplemental 
Figure S8G-I). Compared to WT, cpi1-1 displayed increased expression of ProYUC9:GUS in all the above-mentioned root tissues (Figure 3H; Supplemental Figure S8J-L).

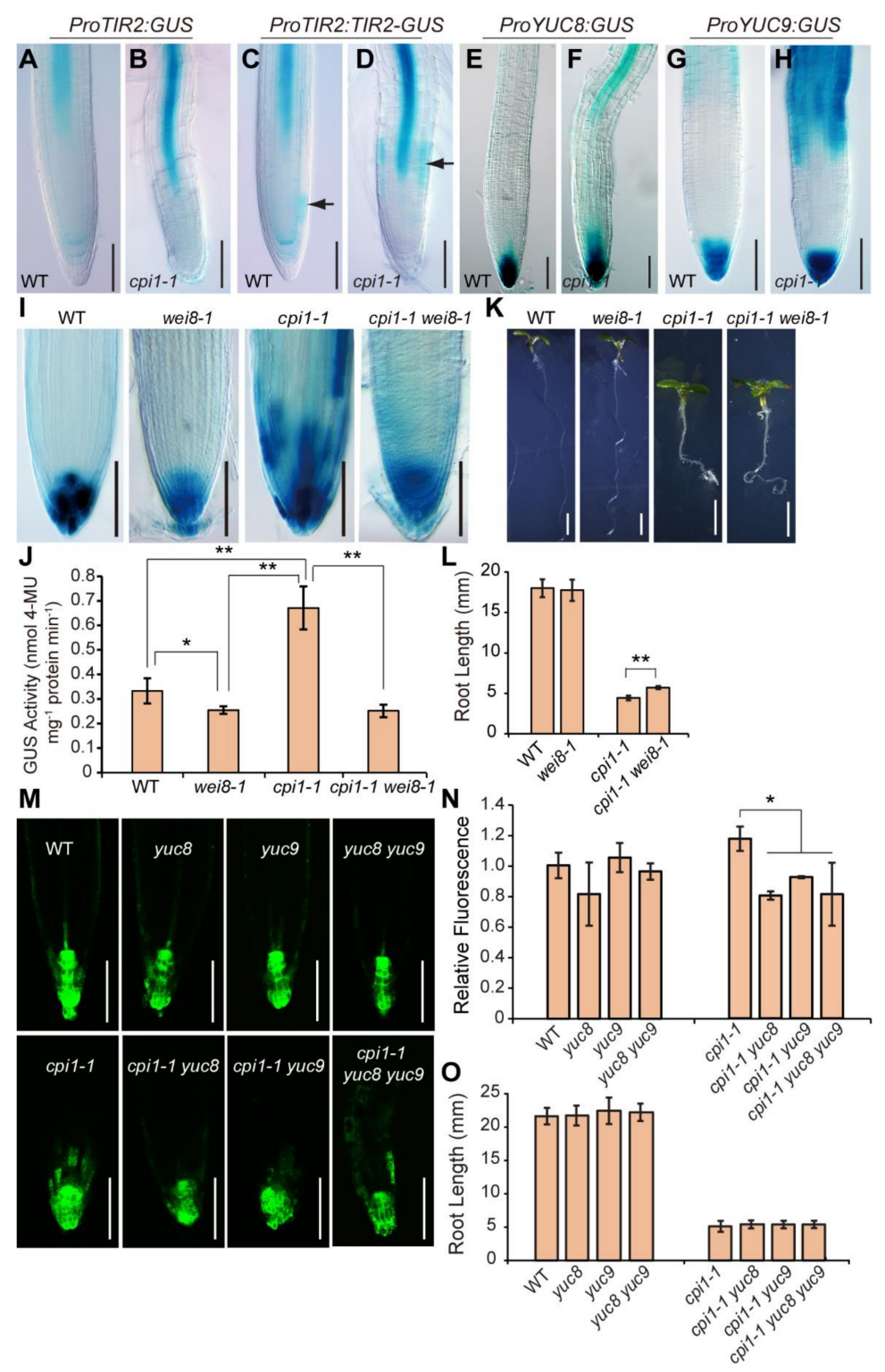

Figure 3. Auxin biosynthesis gene promoter activity is enhanced in cpi1-1 and the cpi1-1 short root phenotype is partially suppressed by the wei8-1 mutation. (A-H) Expression patterns of ProTIR2:GUS, ProTIR2:TIR2-GUS, ProYUC8:GUS, and ProYUC9:GUS in 5-day-old WT and cpi1-1 seedling roots. Shown are representative images of $n=3$ independent experiments (employing 6 to 30 seedlings per experiment). The arrow in (C) indicates GUS staining in the root proximal meristem; The arrow in (D) indicates GUS staining in the elongation zone; (I) Expression patterns of DR5:GUS in root tips of 5-day-old WT, wei8-1, cpi1-1, and cpi1-1 wei8-1 seedlings. Shown are representative images of three independent experiments (employing 18 to 32 seedlings per experiment); (J) Quantitative DR5:GUS activity assay in 5-day-old seedlings. The presented data are means $\pm \mathrm{SD}$ of $n=3$ independent experiments. ${ }^{*} p<0.05,{ }^{* *} p<0.01$ (one-way ANOVA with Tukey's test); (K,L) Phenotypes (K) and root length (L) of 7-day-old seedlings. The presented data are means \pm SD of $n=3$ experiments (employing 13 to 28 seedlings per experiment). ${ }^{* *} p<0.01$ (Student's $t$-test, one-tailed, two-sample equal variance); (M,N) Expression patterns of $D R 5_{r e v}$ :GFP in root tips (M) and quantification of GFP fluorescence (N). The presented data are means \pm SD of $n=3$ independent experiments (employing 6 to 11 roots per experiment). ${ }^{*} p<0.05$ (one-way ANOVA with Tukey's test); (O) Root length of 7-day-old seedlings. The presented data are means \pm SD of $n=3$ independent experiments (employing 9 to 28 seedlings per experiment). No significant difference between cpi1-1 single and cpi1-1 yuc8 and cpi1-1 yuc9 double and cpi1-1 yuc8 yuc9 triple mutants by one-way ANOVA $(p<0.05)$. Bars $=100 \mu \mathrm{m}$ in $(\mathbf{A}-\mathbf{I}, \mathbf{M})$ and $2 \mathrm{~mm}$ in $(\mathbf{K})$. 
We also analyzed the expression of auxin biosynthesis upstream genes including ANTHRANILATE SYNTHASE $\alpha 1$ (ASA1, also known as WEAK ETHYLENE INSENSITIVE2, WEI2) and ANTHRANILATE SYNTHASE $\beta 1$ (ASB1, also known as WEAK ETHYLENE INSENSITIVE7, WEI7), which encode the $\alpha$ - and $\beta$-subunits of a key enzyme of tryptophan biosynthesis [47]. Compared to WT, enhanced expression of ProASB1:GUS was observed in cpi1-1, whereas expression of ProASA1:GUS was not obviously different (Supplemental Figure S9A).

To gain further evidence, RT-qPCR was performed on 7-day-old WT and cpi1-1 seedlings. Consistent with the GUS staining results, TAA1, YUC8, and YUC9 genes showed a significant upregulation in the cpi1-1 mutant (Supplemental Figure S9B). YUC2, ASA1, and ASB1 genes showed a slight, but not significant upregulation in the cpi1-1 mutant (Supplemental Figure S9B).

Together, these results reveal that expression of a number of auxin biosynthesis pathway genes is upregulated in the cpi1-1 mutant, and among them TAA1 and YUC8 genes show cell file specific upregulation.

\subsection{Modulation of Auxin Biosynthesis Partially Rescues the Short Root Phenotype of cpi1-1}

We then investigated whether mutation of auxin biosynthesis genes could reduce the DR5:GUS activity in cpi1-1 and could rescue the short root phenotype of cpi1-1. We found that compared to the cpi1-1 single mutant, DR5:GUS staining was obviously reduced in the cpi1-1 wei8-1 double mutant (Figure 3I). GUS activity quantification results showed that the cpi1-1 wei8-1 double mutant exhibited a similar GUS activity level as the wei81 single mutant (Figure 3J). Consistently, mutation of WEI8/TAA1 partially rescued the short root phenotype of cpi1-1 (Figure 3K,L). We also compared the fluorescent signals of DR5 rev:GFP in cpi1-1 single, cpi1-1 yuc8 and cpi1-1 yuc9 double, and cpi1-1 yuc8 yuc9 triple mutants. We found that $D R 5_{\text {rev }}$ :GFP fluorescence was obviously reduced in cpi1-1 yuc8 and cpi1-1 yuc9 double and in cpi1-1 yuc8 yuc9 triple mutants (Figure $3 \mathrm{M}, \mathrm{N}$ ). However, no significant difference of root length was observed in these mutants (Figure 3O), suggesting that additional YUC genes might play a role. YUC2 and YUC3 mutation also did not affect the hypocotyl length and root length of cpi1-1 (Supplemental Figure S10).

L-Kynurenine (Kyn) is an auxin biosynthesis inhibitor that inhibits TAA1 activity [48]. We thus checked the effect of Kyn on cpi1-1 root growth by growing WT and cpi1-1 seedlings in Murashige and Skoog (MS) media supplemented with a range of concentrations of Kyn $(0,0.5,1,2,3$, and $5 \mu \mathrm{M})$ for 7 days. WT root growth was inhibited by these Kyn treatments especially at higher Kyn concentrations (Figure $4 \mathrm{~A}, \mathrm{~B}$ ). For example, after treatment with 2,3 , and $5 \mu \mathrm{M}$ Kyn, the WT root length was approximately $58 \%, 50 \%$, and $40 \%$ of the mock, respectively. In contrast, cpi1-1 root growth was partially rescued by Kyn treatment, particularly at $0.5,1$, and $3 \mu \mathrm{M}$ Kyn, the cpi1-1 root length was increased by more than $21 \%$ (Figure $4 \mathrm{~A}, \mathrm{~B}$ ). Previous research showed that Kyn treatment inhibited root growth by blocking root meristem function [41]. Therefore, we measured the root meristem size of WT and cpi1-1 seedlings after Kyn treatment. The results showed that size of the meristem zone of WT root was significantly reduced under $5 \mathrm{uM} \mathrm{Kyn}$ treatment, but no statistical difference was observed in the root meristem zone length of cpi1-1 mutant (Figure 4C,D). These results suggest that cpi1-1 is less sensitive to Kyn treatment.

Together, these results demonstrate that genetic and pharmacological inhibition of auxin biosynthesis can partially rescue the short root phenotype of cpi1-1. 
A

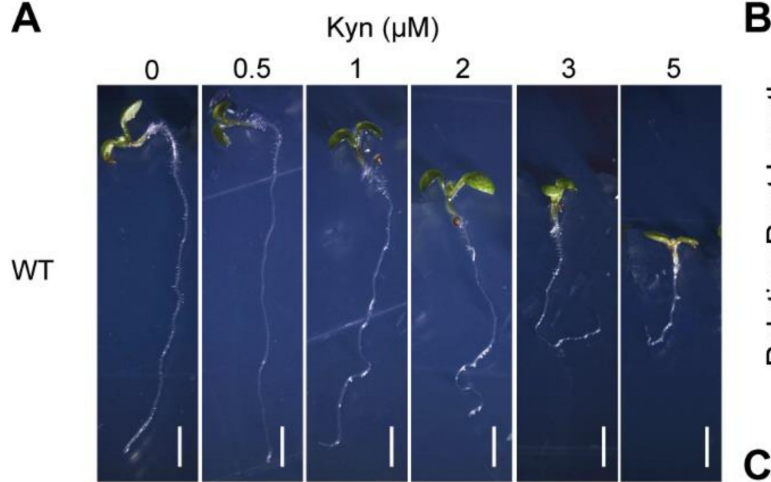

B

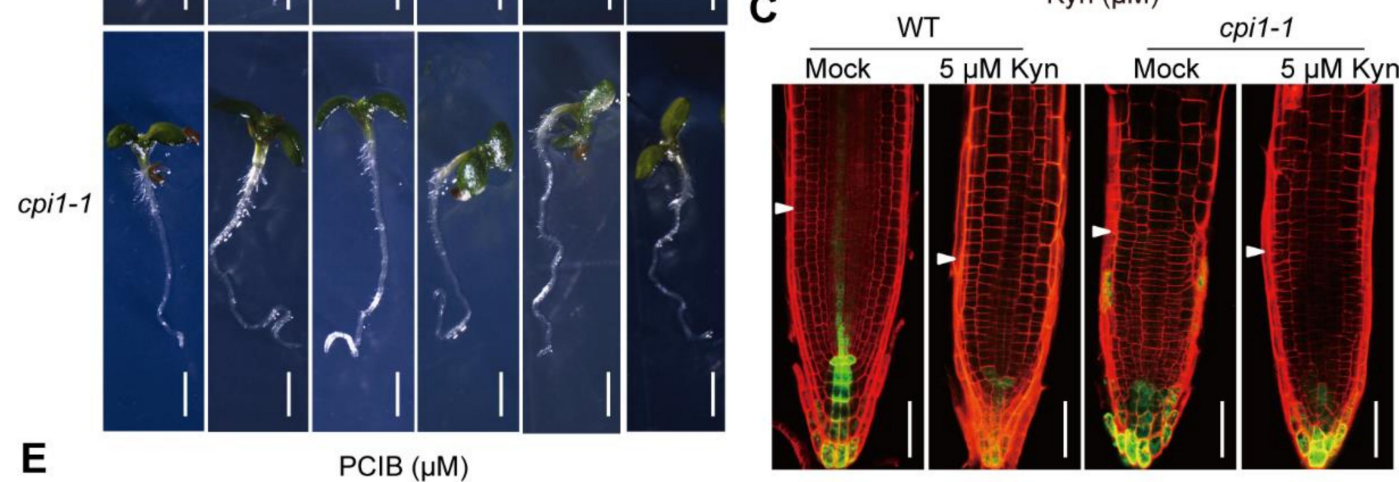

$\mathbf{E}$

$\mathrm{PCIB}(\mu \mathrm{M})$
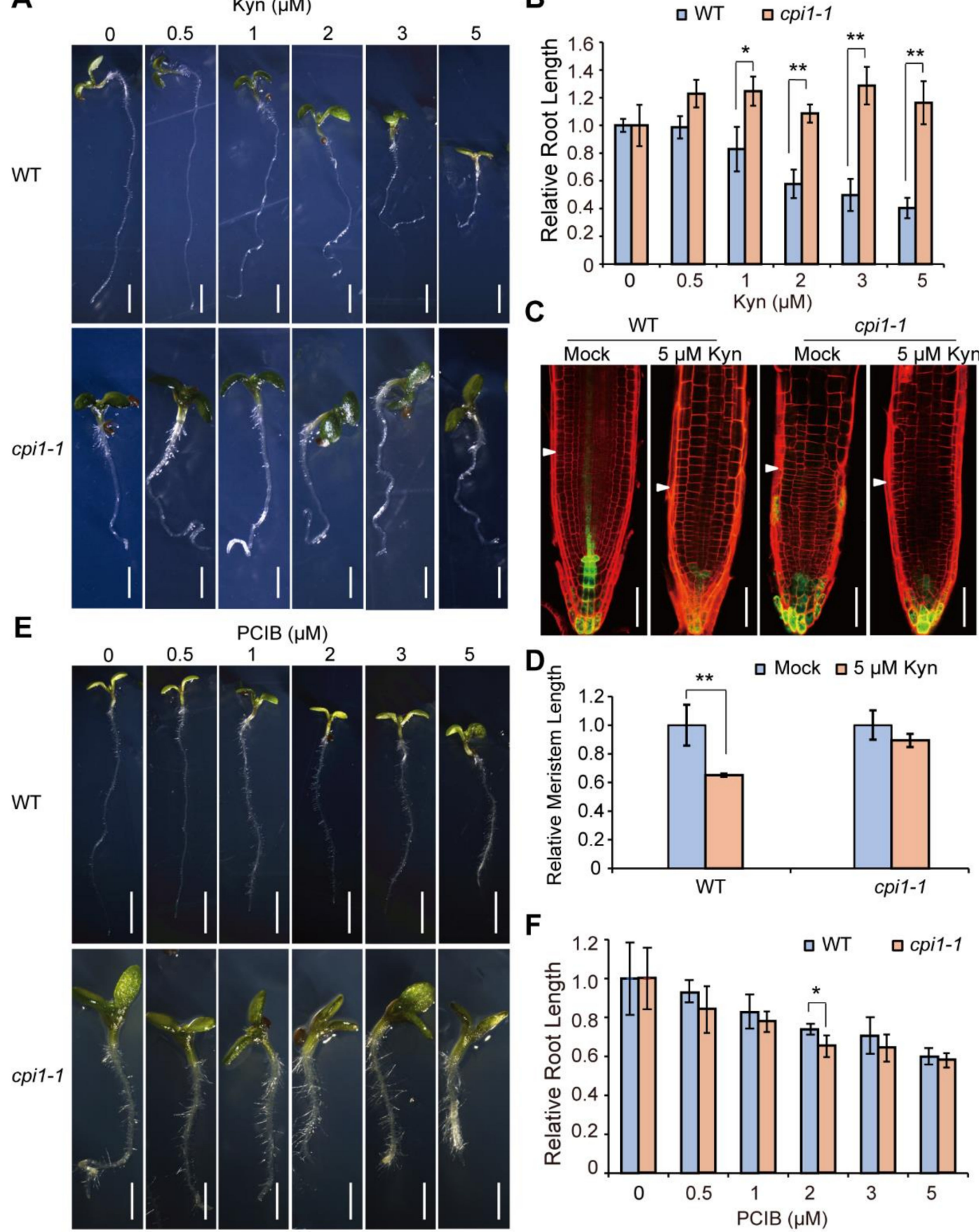

Figure 4. The cpi1-1 short root phenotype is partially rescued by the L-Kynurenine (Kyn) auxin biosynthesis inhibitor, while cpi1-1 responds normally to the $p$-Chlorophenoxyisobutyric acid (PCIB) auxin signaling inhibitor. (A,E) Phenotypes of WT and cpi1-1 seedlings after treatment with various concentrations of Kyn (A) and PCIB (E) for 7 days; (B,F) Relative root length of 7-day-old WT and cpi1-1 seedlings grown on MS medium supplemented with different concentrations of Kyn (B) and PCIB (F). MS medium supplemented with $0.1 \mathrm{mM} \mathrm{HCl}$ and $0.1 \%(v / v)$ ethanol, solvent for Kyn and PCIB, respectively, served as blank controls. The presented data are means \pm SD of $n=3$ independent experiments (employing 8 to 55 seedlings per experiment. ${ }^{*} p<0.05,{ }^{* *} p<0.01$ (one-way ANOVA with Tukey's test); (C) Meristem architectures of 7-day-old WT and cpi1-1 seedling roots grown on MS medium supplemented with or without $5 \mu$ M Kyn; (D) Relative meristem zone length of 7-day-old seedling roots. The presented data are means \pm SD of $n=3$ independent experiments (employing 18 to 28 roots per experiment). ${ }^{* *} p<0.01$ (Student's $t$-test, one-tailed, two-sample equal variance). Bars $=2 \mathrm{~mm}$ in (A,E, top panel), $1 \mathrm{~mm}$ in (A,E, bottom panel), and $50 \mu \mathrm{m}$ in (C). 


\section{4. cpi1-1 Responds Normally to the Auxin Signaling Inhibitor}

$p$-Chlorophenoxyisobutyric acid (PCIB) is an auxin signaling inhibitor [49]. To investigate whether CPI1 mutation has an effect on auxin signaling, we grew WT and cpi1-1 seedlings in MS media supplemented with different concentrations of PCIB $(0,0.5,1,2$, 3 , and $5 \mu \mathrm{M}$ ) for 7 days. We found that root growth of both WT and cpi1-1 were inhibited by PCIB treatment, and their relative root length showed no significant difference (Figure 4E,F), indicating that cpi1-1 roots respond normally to the auxin signaling inhibitor. These data suggest that cpi1-1 mutation may not affect the auxin signaling.

\subsection{Cycloeucalenol Application Increases the Expression of Auxin Biosynthesis Genes}

Previously, Men et al. (2008) demonstrated that sterol composition was markedly altered in the cpi1-1 plants. Cycloeucalenol, a minor sterol component in WT $(1.0 \mu \mathrm{g} / \mathrm{g}$ fresh weight $(\mathrm{fw}))$, was detected as a major sterol compound in cpi1-1 $(50.3 \mu \mathrm{g} / \mathrm{g} \mathrm{fw})$ [8]. By contrast, sitosterol, the predominant sterol in WT $(122.3 \mu \mathrm{g} / \mathrm{g} \mathrm{fw})$, was reduced to trace amounts in cpi1-1 (2.5 $\mu \mathrm{g} / \mathrm{g} \mathrm{fw})$. 24-methylcholesterol (campesterol) and stigmasterol, the other two major sterols in WT (22.4 and $10.3 \mu \mathrm{g} / \mathrm{g} \mathrm{fw}$, respectively), were undetectable in cpi1-1 [8]. We wondered whether these alterations of sterol composition caused the upregulation of auxin biosynthesis in cpi1-1. To address this, we performed cycloeucalenol treatment on ProTIR2:GUS, ProYUC8:GUS, ProYUC9:GUS, and DR5:GUS expressing seedlings. Upon cycloeucalenol treatment $(1 \mu \mathrm{M})$, the GUS staining of ProTIR2:GUS and DR5:GUS was obviously stronger than that of the mock $(0.1 \%$ acetone $(v / v)$, the solvent for cycloeucalenol) (Figure 5A-D,I,J). The GUS signals were also slightly enhanced in the ProYUC8:GUS and ProYUC9:GUS lines treated with cycloeucalenol (Figure 5E-H). To gain further evidence, we performed quantitative GUS activity assay. The results showed that after cycloeucalenol treatment, the GUS activity in ProTIR2:GUS, ProYUC8:GUS, and DR5:GUS seedlings was significantly increased, but no statistical difference was observed in ProYUC9:GUS with or without cycloeucalenol treatment (Figure 5K). In RT-qPCR analysis, YUC8 and TAA1 genes also showed significant upregulation after cycloeucalenol treatment, whereas YUC9 gene showed a slight, but not significant upregulation upon cycloeucalenol treatment (Supplemental Figure S11A). RT-qPCR was also performed to determine whether cycloeucalenol affects the expression of PAT genes. The results showed that the expression of PIN genes and $A U X 1 / L A X$ genes was not significantly different between mock and cycloeucalenol treatments (Supplemental Figure S11B). These results indicate that while cycloeucalenol can contribute to upregulation of the expression of auxin biosynthesis genes, it does not affect PIN and AUX1/LAX gene expression.

\subsection{Sitosterol Application Decreases DR5:GUS and ProYUC8:GUS Expression and Partially Rescues the cpil-1 Short Root Phenotype}

To investigate whether sitosterol affects auxin biosynthesis gene expression, RT-qPCR was performed on 5-day-old WT seedlings grown on MS medium supplemented with or without sitosterol. The results showed that the expression of YUC 8 was reduced by sitosterol treatment, whereas the expression of $Y U C 9$ and TAA1 was not significantly different between mock and sitosterol treatments (Supplemental Figure S12A). To gain further evidence, we compared the expression of ProTIR2:GUS, ProYUC8:GUS, and ProYUC9:GUS between mock and sitosterol treatments. Consistent with the RT-qPCR results, after sitosterol treatment the GUS staining and GUS activity of ProYUC8:GUS was obviously reduced (Figure 6A,C), whereas ProTIR2:GUS and ProYUC9:GUS displayed no obvious difference between mock and sitosterol treatments (Supplemental Figure S12B). Consistently, sitosterol repressed expression of DR5:GUS in both WT and cpi1-1 roots (Figure 6B,D). We then investigated whether sitosterol was involved in regulating auxin transport by examining the transcript levels of auxin transporters after sitosterol treatment. The results revealed that, except for PIN7, the expression of none of the other PIN and AUX/LAX genes examined was altered after sitosterol treatment (Supplemental Figure S12C). We then investigated whether the root length of cpi1-1 was influenced by sitosterol. Application 
of sitosterol slightly repressed the root growth of WT, but partially rescued the short root phenotype of cpi1-1 (Figure 6E,F).

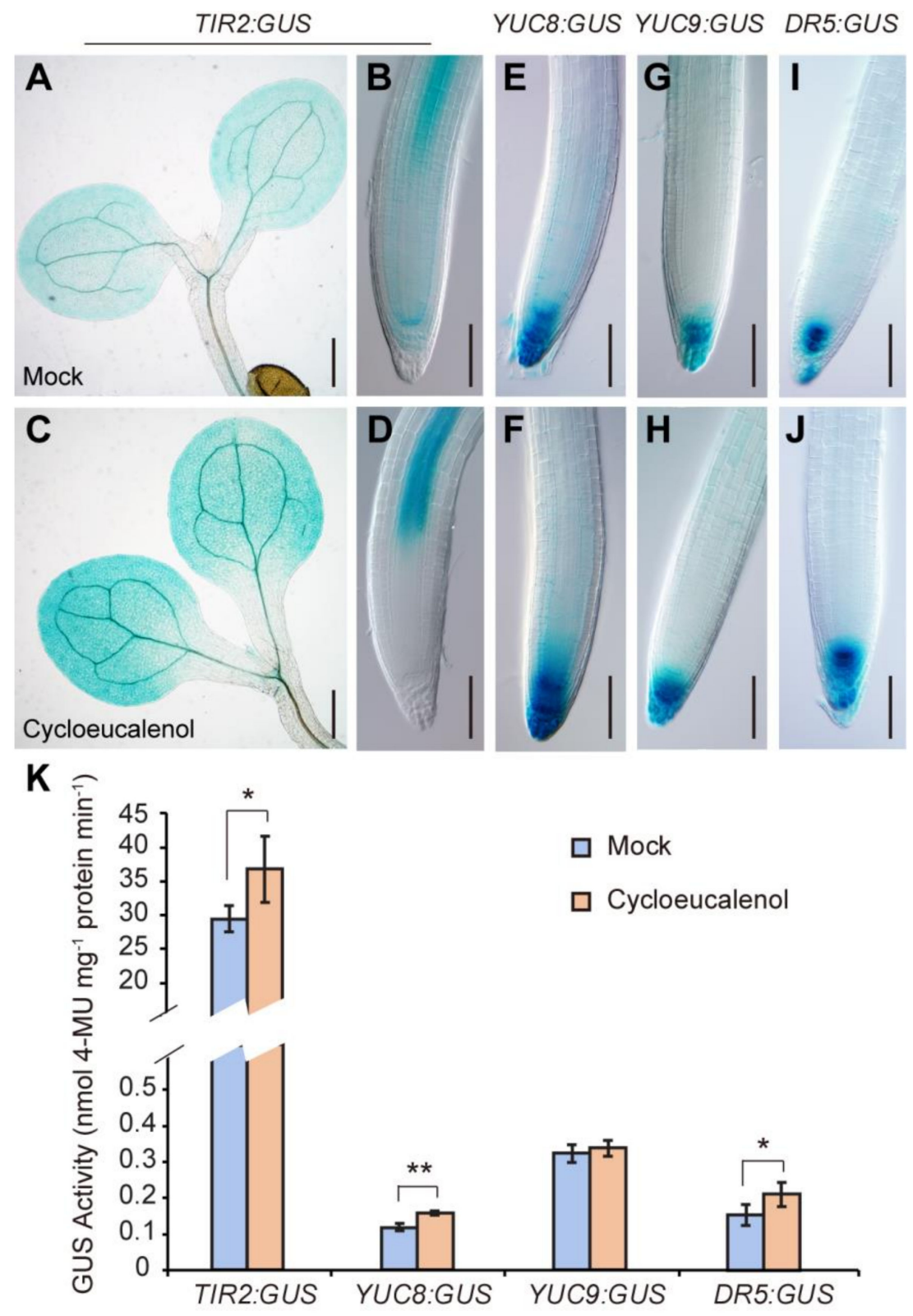

Figure 5. Cycloeucalenol enhances auxin biosynthesis genes and DR5:GUS auxin response reporter expression. (A-D) Expression patterns of ProTIR2:GUS in shoots (A,C) and root tips (B,D) of 5day-old WT seedlings grown on MS medium containing $0.1 \%$ acetone solvent (mock) or $1 \mu \mathrm{M}$ cycloeucalenol. Shown are representative images of three independent experiments (employing 11 to 26 seedlings per experiment); (E-J) Expression patterns of ProYUC8:GUS (E,F), ProYUC9:GUS $(\mathbf{G}, \mathbf{H})$, and DR5:GUS (I,J) in root tips of 5-day-old WT seedlings grown on MS medium containing $0.1 \%(v / v)$ acetone solvent (mock) or $1 \mu \mathrm{M}$ cycloeucalenol. Shown are representative images of three independent experiments (employing 10 to 26 seedlings per experiment); (K) GUS activity of ProTIR2:GUS, ProYUC8:GUS, ProYUC9:GUS, and DR5:GUS 5-day-old seedlings. The presented data are means $\pm \mathrm{SD}$ of $n=3$ independent experiments. ${ }^{*} p<0.05,{ }^{* *} p<0.01$ (Student's $t$-test, one-tailed, two-sample equal variance). Bars $=400 \mu \mathrm{m}$ in $(\mathbf{A}, \mathbf{C})$ and $100 \mu \mathrm{m}$ in (B,D-J). 
A ProYucz:Gus B

B $\frac{\text { DR5:GUS /WT }}{\text { Mock } 1.5 \mu \mathrm{gL}^{-1} 3 \mu \mathrm{g} \mathrm{mL}}$
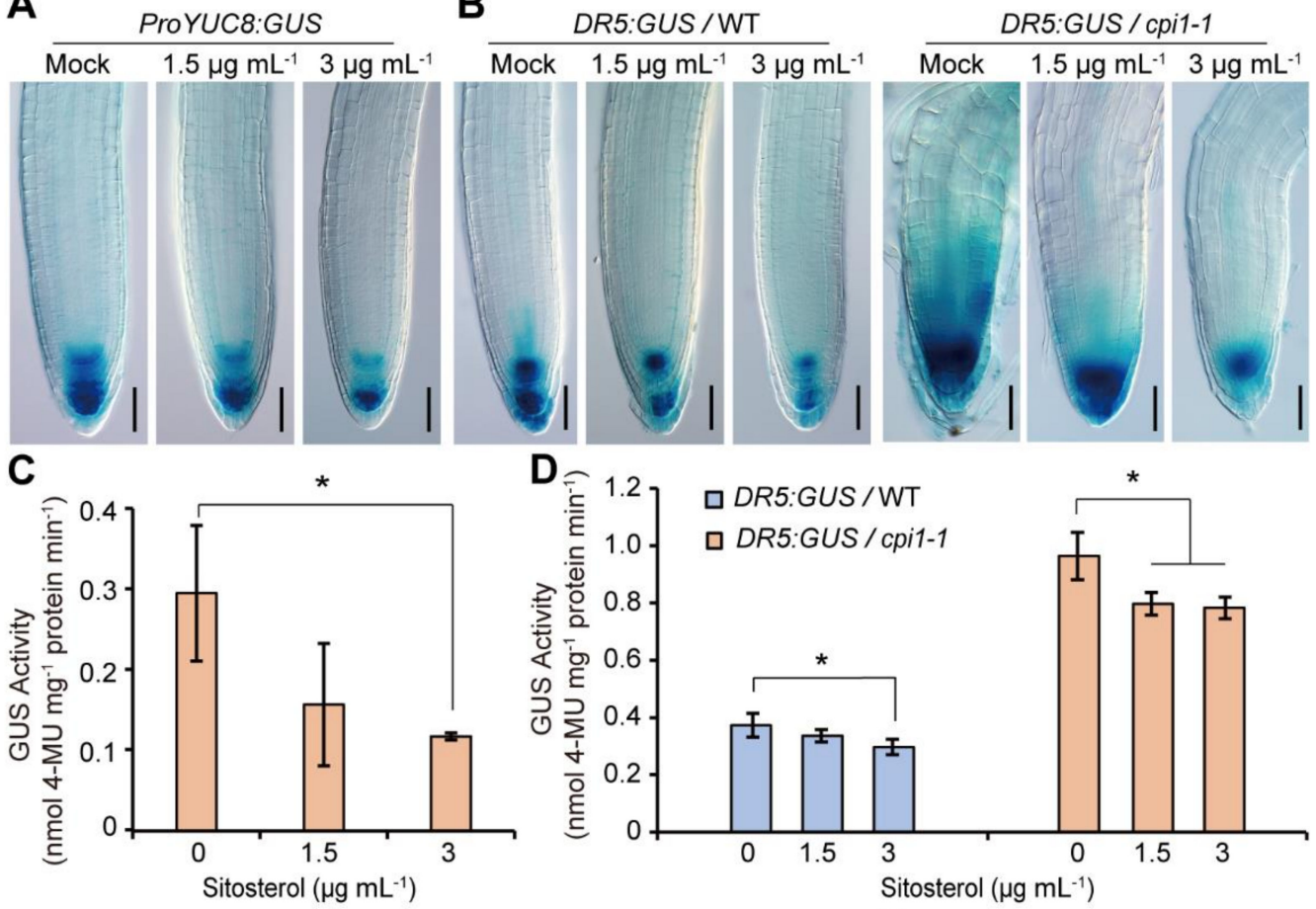

E

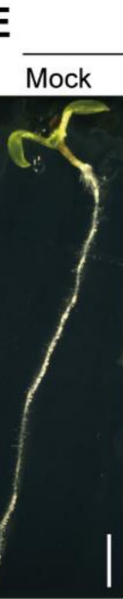

WT
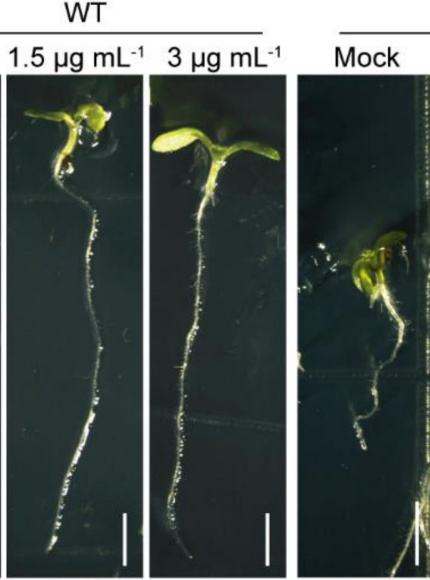

cpi1-1

Sitosterol $\left(\mu \mathrm{g} \mathrm{mL} \mathrm{L}^{-1}\right)$

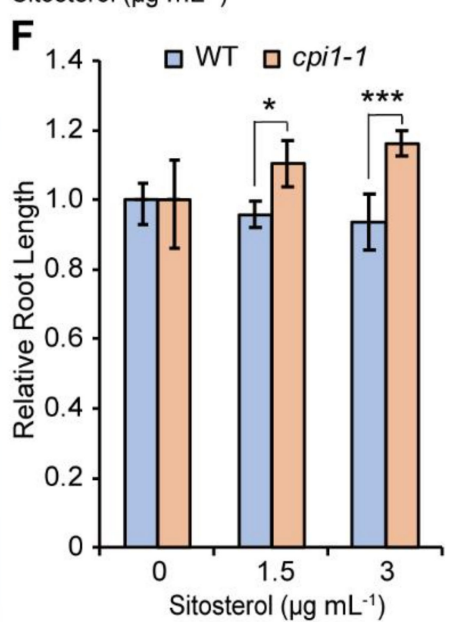

Figure 6. Sitosterol represses the expression of ProYUC8:GUS and DR5:GUS, and partially rescues the short root phenotype of cpi1-1. (A) Expression of ProYUC8:GUS treated with or without sitosterol. The images are representative of $n=3$ independent experiments employing 9 to 30 seedlings per experiment; (B) Expression of DR5:GUS in WT and cpi1-1 seedlings treated with or without sitosterol. The images are representative of $n=3$ independent experiments employing 14 to 30 seedlings per experiment; (C,D) Quantitative GUS activity assay of ProYUC8:GUS (C) and DR5:GUS (D) in 5-day-old seedlings. Data are shown as means $\pm \mathrm{SD}$ of $n=3$ independent experiments. ${ }^{*} p<0.05$ (one-way ANOVA with Tukey's test); (E,F) Phenotypes (E) and relative root length (F) of WT and cpi1-1 seedlings grown on MS medium supplemented with different concentrations of sitosterol. Data are shown as means \pm SD of $n=3$ experiments (employing 12 to 45 roots per experiment). ${ }^{*} p<0.05,{ }^{* * *} p<0.001$ (Student's $t$-test, one-tailed, two-sample equal variance). Bars $=100 \mu \mathrm{m}$ in $(\mathbf{A}, \mathbf{B})$ and $1 \mathrm{~mm}$ in $(\mathbf{E})$.

To determine whether stigmasterol and cholesterol affect the root growth of cpi1-1, we measured the root length of 7-day-old WT and cpi1-1 seedlings grown on MS medium supplemented with or without stigmasterol or cholesterol. Stigmasterol repressed the root elongation of both WT and cpi1-1, while cholesterol showed no detectable influence on root growth (Supplemental Figure S13).

Taken together, our results suggest that cycloeucalenol and sitosterol have opposite effects on auxin biosynthesis and activity (Figure 7). 


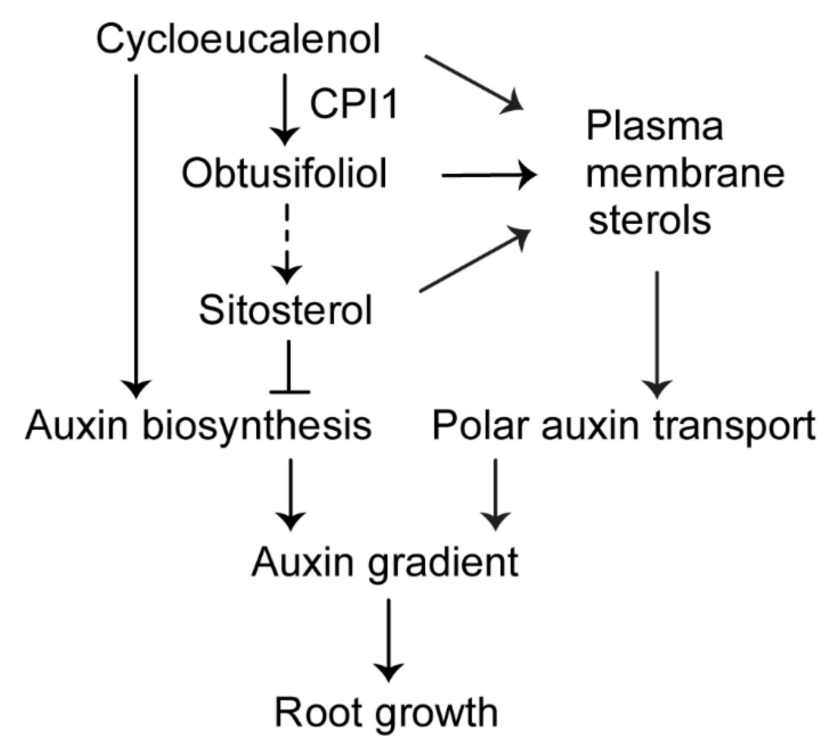

Figure 7. A working model for the role of CPI1 in Arabidopsis root growth. In the plant sterol biosynthesis pathway, CPI1 catalyzes the conversion of cycloeucalenol into obtusifoliol, which is further metabolized to sitosterol. Cycloeucalenol upregulates the expression of auxin biosynthesis genes; by contrast, sitosterol represses the expression of these genes. Normal content of cycloeucalenol and sitosterol is important for optimal auxin biosynthesis, and correct plasma membrane sterol composition is required for normal polar auxin transport. Auxin biosynthesis and polar auxin transport cooperatively establish an optimal auxin gradient in the root tip to regulate root growth.

\section{Discussion}

\subsection{Auxin Activity and Auxin Biosynthesis are Increased in the cpi1-1 Mutant}

The cpi1-1 mutant displayed enhanced and ectopic DR5:GUS expression in the root tip [8], suggesting that either auxin signaling is enhanced in the cpi1-1 mutant or its root tip accumulates more auxin. We found that the cpi1-1 mutant responds normally to the auxin signaling inhibitor, so it is unlikely that auxin signaling is enhanced in cpi1-1. The DR5:GUS expression patterns in cpi1-1 root tip resembled that of pin2-T mutant and polar PIN2 localization was disrupted in cpi1-1 root tip epidermis and cortex cells [8], suggesting that defective PAT caused auxin accumulation in the cpi1-1 root tip. However, our genetic experiments showed that DR5:GUS signals in cpi1-1 pin2-T double mutant root tips was stronger than either cpi1-1 or pin2-T single mutant, indicating an additive effect. This finding suggests that defective PAT alone cannot explain the increased levels of auxin in the roots of cpi1-1 mutants. Indeed, we found that expression of auxin biosynthesis genes including TAA1, YUC8, and YUC9 was upregulated in the cpi1-1 mutant. These results suggest that altered sterol composition in the cpi1-1 mutant not only affects PAT but also affects auxin biosynthesis.

A recent report showed that in rice, low membrane sterol levels compromised the interaction between the ethylene receptor OsERS2 and the inhibitory kinase OsCTR2 in the ER membrane, thus activates the ethylene response [50]. It has been known that ethylene upregulates auxin biosynthesis [51-54]. Thus, reduced membrane sterol content might upregulate auxin biosynthesis through activation of ethylene signaling. The cpi1-1 mutant displays an almost complete replacement of the usual $\Delta^{5}$-sterols including sitosterol, campesterol, and stigmasterol by $9 \beta, 19$-cyclopropyl sterols, but its total sterol content is not reduced compared to that of the WT (285 $\mu \mathrm{g} / \mathrm{g}$ fw in cpi1-1 versus $190 \mu \mathrm{g} / \mathrm{g}$ fw in WT) [8]. The next step should analyze whether ethylene signaling is affected in the cpi1-1 mutant to determine if altered sterol composition also has an effect on ethylene signaling. 


\subsection{Cycloeucalenol Might Play a Role in Plant Development}

In vertebrates and fungi, lanosterol synthase (LAS) cyclizes 2,3-oxidosqualene to the tetracyclic lanosterol, which is further metabolized to tetracyclic cholesterol and ergosterol, respectively, whereas in plants, 2,3-oxidosqualene is mainly cyclized to the pentacyclic cycloartenol (which contains a 9 $\beta, 19$-cyclopropane ring) by cycloartenol synthase (CAS) $[3,55,56]$. After C-24 methylation and C-4 demethylation, cycloartenol is converted to cycloeucalenol [3]. Then, CPI1 catalyzes the opening of the 9ß,19-cyclopropane ring of cycloeucalenol, and converts it to tetracyclic obtusifoliol [29], which is further metabolized to tetracyclic end-products such as sitosterol and stigmasterol (Supplemental Figure S1). Why plants use this two-enzyme route instead of cyclizing directly to tetracyclic sterols and whether those $9 \beta, 19$-cyclopropyl sterols have physiological roles are long-standing questions that remain to be answered. Several 9 9,19 -cyclopropyl sterols, including cycloartenol, 24-methylene cycloartanol, and cycloeucalenol, are indeed present as minor sterol compounds in plants $[2,6-10,57]$. During male gametophyte development, the tetrads have similar sterol species as vegetative organs, but mature pollen cells accumulate esterified 9 $\beta, 19$-cyclopropyl sterols [58,59]. CAS1 loss of function leads to male-specific transmission defect [55]. These results suggest that $9 \beta, 19$-cyclopropyl sterols might have a role in male gametophyte development and transmission. Interestingly, cycloeucalenol was found to be the major newly synthesized sterol during pollen cells germination and its accumulation increased with pollen tube elongation $[58,59]$. Furthermore, inhibition of cycloeucalenol synthesis inhibited pollen tube elongation [58]. Mutants upstream of CPI1 such as hmg1 also showed defects in pollen cells germination and pollen tube elongation [60]. These findings strongly suggest that cycloeucalenol is required for pollen cells germination and pollen tube growth. How cycloeucalenol contributes to pollen cells germination and pollen tube elongation is so far unknown. Like pollen tubes, root hairs also grow in a polarized fashion. Whether cycloeucalenol is also involved in root hair growth is unknown. Recently, it has been reported that induced accumulation of a 9 $\beta, 19$-cyclopropyl sterol, 4-carboxy-4methyl24-methylenecycloartanol (CMMC), by loss-of-function of ERGOSTEROL BIOSYNTHETIC PROTEIN28 (ERG28) led to phenotypes resemble of those caused by defective PAT, including inhibited root growth, pin-like inflorescence, and fused leaves [10]. Furthermore, exogenous application of CMMC inhibited PAT [10]. Since CMMC was not detectable in WT at normal growth conditions, further investigations are required to determine at what circumstances it is released to regulate PAT. In this study, we found that increased content of cycloeucalenol in cpi1-1 was associated with enhanced auxin biosynthesis and response. Furthermore, in vitro application of cycloeucalenol upregulated the expression of auxin responsive reporter DR5:GUS and auxin biosynthesis genes such as TAA1/TIR2 and YUC8. These results imply that cycloeucalenol might play a role in plant development and growth by regulating auxin biosynthesis. Further investigations are required to understand how cycloeucalenol upregulates auxin biosynthesis.

\subsection{Sitosterol Modulates Auxin Biosynthesis and Response}

Previous studies have shown that a number of sterol mutants exhibit aberrant auxin response and polar auxin transport due to altered sterol composition $[8,9,19,21,22,25,27]$. However, whether a certain sterol component has a function in regulating auxin activity is largely unknown. Sitosterol, campesterol, and stigmasterol are the most abundant endproducts of the plant sterol biosynthesis pathway [2-5]. It has been found that in vitro application of sitosterol and stigmasterol enhanced the expression of genes involved in cell expansion and cell division [61]. Exogenous application of sitosterol and stigmasterol but not campesterol partially rescued the abnormal auxin-induced lateral root development in the smt 2 smt 3 double mutant [26]. Further research demonstrated that application of sitosterol restored the DR5:GUS signal gradient in the lateral root tips of the smt2 smt3 mutant, suggesting that directional auxin transport was amended by sitosterol [26]. These results were consistent with the altered sterol profiles in the smt 2 smt 3 mutant, as in this mutant the sitosterol and stigmasterol content were reduced to trace amount, whereas the 
campesterol content was increased [9]. Similarly, in cpi1-1, sitosterol content was reduced to trace amount, whereas stigmasterol and campesterol were undetectable [8]. We found that the aberrant sterol profile in cpi1-1 was associated with increased auxin biosynthesis in addition to defective PAT. Further analysis showed that sitosterol application reduced the expression of auxin biosynthesis genes and an auxin responsive reporter and partially rescued the short root phenotype of cpi1-1. These results suggest that sitosterol functions in regulating auxin activity by inhibiting auxin biosynthesis. How sitosterol regulates the expression of auxin biosynthesis genes remains to be determined. In animals, cholesterol stimulates the autoprocessing of the precursor protein of the Hedgehog $(\mathrm{Hh})$ morphogen important for embryo development. Cholesterol covalently attaches to the N-terminus of the mature Hh protein, which is essential for the long-range activity of Hh [62,63]. Recently, Xiao et al. (2017) found that the Hh signaling pathway downstream protein Smoothened (SMO) was also covalently modified by cholesterol, which activates SMO [64]. In plants, no sitosterol-binding protein has been identified so far. Interestingly, a recent study found that the early gravistimulation induced ROSY1 protein contains a MD2-lipid binding domain and specifically binds stigmasterol in vitro [65]. Mutation of ROSY1 leads to decreased basipetal auxin transport and enhanced gravitropic response [65]. Screens for sitosterolbinding proteins should provide insights for understanding the roles of sitosterol in plant growth and development.

Overall, our findings suggest that cycloeucalenol upregulates, whereas sitosterol downregulates auxin biosynthesis. The altered sterol composition in cpi1-1 leads to enhanced auxin biosynthesis and defective polar auxin transport, resulting in an enhanced, ectopic auxin gradient in the cpi1-1 root tip accompanied by altered root growth. Hence, our findings provide an initial mechanistic basis for future studies on the molecular mechanisms by which sterols influence auxin biosynthesis in plants.

\section{Materials and Methods}

\subsection{Plant Materials and Growth Conditions}

Arabidopsis thaliana (Arabidopsis) ecotype Columbia (Col-0) and Landsberg erecta (Ler) were used as the wild type (WT). The following mutants were used in this study: cpi1-1 transposon insertion mutant in the Ler background [8] and cpi1-1 out-crossed to the Col-0 background [66], T-DNA insertion mutants pin2-T [8], aux1-T [34], yuc2 (SALK_030199) [45], wei8-1 [38], and yuc8 (SALK_096110) and yuc9 (SAIL_871_G01) [67,68] are in Col-0 background. These mutants were verified by PCR-based genotyping using primers listed in Supplemental Table S1. The following transgenic reporter lines were used in this study: DR5:GUS [32,33], DR5 rev:GFP [69], ProPIN1:GUS and ProPIN7:GUS [70], ProPIN3:GUS [71], ProPIN4:GUS [72], PIN7-GFP [73], ProASA:GUS and ProASB:GUS [47], ProTAA1:GFPTAA1 [38], ProTIR2:GUS and ProTIR2:TIR2-GUS [40], ProYUC2:GUS and ProYUC4:GUS [45], and ProYUC8:GUS and ProYUC9:GUS [46]. Arabidopsis seeds were surfaced sterilized first with $70 \%(v / v)$ ethanol (Sangon Biotech, Shanghai, China) for $5 \mathrm{~min}$, then with $1 \%(v / v)$ $\mathrm{NaClO}$ (Sangon Biotech, Shanghai, China) for $10 \mathrm{~min}$, washed five times with sterile water, incubated for 3-4 days at $4{ }^{\circ} \mathrm{C}$, and sowed on Murashige Skoog (MS) medium (pH 5.8) (Duchefa Biochemie, Haarlem, Netherlands) supplemented with 1\% (w/v) sucrose (Sangon Biotech, Shanghai, China) and solidified by $0.8 \%$ ( $w / v)$ agar (Duchefa Biochemie, Haarlem, Netherlands). The seeds were germinated and grown at $22{ }^{\circ} \mathrm{C}$ under a $16 \mathrm{~h}$ light $/ 8 \mathrm{~h}$ dark photoperiod with $90-110 \mu \mathrm{mol} \mathrm{m} \mathrm{m}^{-2} \mathrm{~s}^{-1}$ illumination.

\subsection{GUS Staining}

GUS expression of various genotypes were detected by incubating 5 -day-old seedlings of various plant lines in a staining solution $\left(0.5 \mathrm{mg} \mathrm{mL}^{-1}\right.$ 5-bromo-4-chloro-3-indolyl$\beta$-D-glucuronic acid, $50 \mathrm{mM}$ sodium phosphate, $0.5 \mathrm{mM}$ ferricyanide, and $0.1 \%(v / v)$ Triton X-100, $\mathrm{pH} 7.0$ ) at $37^{\circ} \mathrm{C}$ for various hours (indicated below). After incubation, the samples were first fixed in ethanol:acetic acid $(2: 1)$ for $6 \mathrm{~h}$, then were cleared in a clearing solution of 8:3:1 $(w / v / v)$ chloral hydrate:distilled water:glycerol. The samples 
were observed using an Olympus BX63 (Olympus Corporation, Tokyo, Japan) microscope. The incubation hours for different transgenic lines in the GUS staining solution are as follows: $12 \mathrm{~h}$ (WT and mutants in Figures 1-3) or $3 \mathrm{~h}$ (the sterols treatment experiments in Figures 5 and 6) for DR5:GUS, $3 \mathrm{~h}$ for ProTIR2:GUS and ProTIR2:TIR2-GUS, $36 \mathrm{~h}$ for ProPIN1:GUS, 6 h for ProPIN3:GUS, 1 h for ProPIN4:GUS, ProPIN7:GUS, ProASA1:GUS, and ProYUC8:GUS, and $2 \mathrm{~h}$ for ProASB1:GUS and ProYUC9:GUS. Analysis was done in biological triplicate. 5-bromo-4-chloro-3-indolyl- $\beta$-D-glucuronic acid was purchased from Bio Basic Inc (Toronto, Canada), other reagents used in this part were purchased from Sangon Biotech (Shanghai, China).

\subsection{Fluorescence Microscopy}

GFP fluorescence was observed either using a fluorescent microscope (Olympus BX63, Olympus Corporation, Tokyo, Japan) or by a confocal laser scanning microscope (Leica TCS SP5, Wetzlar, Germany) using $488 \mathrm{~nm}$ excitation filter with $505-550 \mathrm{~nm}$ band pass. Images were processed with Adobe Photoshop CS5 and assembled in Adobe Illustrator CS4.

\subsection{Auxin Inhibitor Treatments}

For 1-N-naphthylphthalamic acid (NPA) treatments, WT and cpi1-1/+ seeds were germinated and grown for 7 days on MS medium supplemented with different concentrations of NPA $(0,250$, and $500 \mathrm{nM}$ ) for 7 days. NPA was dissolved in DMSO (Sangon Biotech, Shanghai, China). For L-Kynurenine (Kyn) treatments, WT and cpi1-1/+ seeds were germinated on MS medium supplemented with different concentrations of Kyn (0, 0.5, $1,2,3$, and $5 \mu \mathrm{M}$ ) for 7 days. Kyn was dissolved in $0.1 \mathrm{M} \mathrm{HCl}$ (Sangon Biotech, Shanghai, China). For $p$-chlorophenoxyisobutyric acid (PCIB) treatments, WT and cpi1-1/+ seeds were germinated on MS medium supplemented with different concentrations of PCIB $(0,0.5,1$, 2,3 , and $5 \mu \mathrm{M}$ ) for 7 days. PCIB was dissolved in absolute ethanol. NPA, Kyn, and PCIB were purchased from Sigma-Aldrich (Shanghai, China).

\subsection{RNA Extraction and Reverse Transcription Quantitative PCR (RT-qPCR)}

Total RNA was extracted from 7-day-old seedlings by TRIzol according to the manufacturer's instructions (TransGen Biotech, Beijing, China). For RT-qPCR analysis, approximately $2.5 \mu \mathrm{g}$ of total RNA was reverse-transcribed into cDNA using the EasyScript First-Strand cDNA Synthesis SuperMix (TransGen Biotech, Beijing, China). One microliter of each cDNA sample was mixed with $7.5 \mu$ SYBR Green Real-Time PCR Master Mix (DBI Bioscience, Shanghai, China), and then analyzed on a fluorescent quantitative PCR machine (Eppendorf, Hamburg, Germany). The TAP42 INTERACTING PROTEIN OF 41 KDA (TIP41, AT4G34270) gene was used as an internal control. The relative transcription level was calculated by the $2^{-\Delta \Delta \mathrm{Ct}}$ (Ct, cycle threshold) value. Primers used in the RT-qPCR analysis are listed in Supplemental Table S1.

\subsection{Sterol Treatment}

For cycloeucalenol and sitosterol treatments, ProTIR2:GUS, ProYUC8:GUS, ProYUC9:GUS, and DR5:GUS seeds were germinated and grown for 5 days on cycloeucalenol- or sitosterolcontaining MS medium ( $\mathrm{pH} 5.8)$ solidified by $0.8 \%(w / v)$ agar. Seedlings were then collected for GUS staining. The concentrations of sterols used were according to previous publications [26,60]. Cycloeucalenol (purchased from BioBioPha, Kunming, China) was dissolved in absolute acetone (Sangon Biotech, Shanghai, China) and added to the MS medium at $1 \mu \mathrm{M}$ final concentration. The same MS medium supplemented with $0.1 \%(v / v)$ acetone was used as control. Sitosterol (purchased from TCI Shanghai, Shanghai, China) was dissolved in absolute chloroform (Sangon Biotech, Shanghai, China) and added to the MS medium at 1.5 or $3 \mu \mathrm{g} \mathrm{mL}{ }^{-1}$ final concentrations. The same MS medium supplemented with $0.1 \%(v / v)$ chloroform was used as control. For stigmasterol and cholesterol treatments, WT and cpi1-1 seeds were germinated and grown for 7 days on stigmasterolor cholesterol-containing MS medium ( $\mathrm{pH} 5.8)$ solidified by $0.8 \%(w / v)$ agar. Stigmas- 
terol (purchased from TCI Shanghai, Shanghai, China) and cholesterol (purchased from Sigma-Aldrich, Shanghai, China) were dissolved in absolute chloroform and added to the MS medium at 1 or $10 \mu \mathrm{M}$ final concentrations, respectively. The same MS medium supplemented with $0.1 \%(v / v)$ chloroform was used as control.

\subsection{Statistical Analyses}

Three independent repetitions were conducted for all experiments. Statistical analyses were performed by using one-tailed Student's $t$-test or using one-way analysis of variance (ANOVA) with Tukey's test. All values are presented as means \pm SD. Significant differences are noted as follows: ${ }^{*} p<0.05,{ }^{* *} p<0.01$, and ${ }^{* * *} p<0.001$.

\subsection{Accession Numbers}

Sequence data from this article for the cDNA and genomic DNA of CPI1 can be found in The Arabidopsis Information Resource database (https:/ / www.arabidopsis.org/) under accession number At5g50375. T-DNA insertion lines used for mutant analyses were as follows: pin2-T (SALK_091142), aux1-T (SALK_020355), yuc2 (SALK_030199), wei8-1 (CS16407), yuc8 (SALK_096110), and yuc9 (SAIL_871_G01).

Supplementary Materials: Supplementary Materials can be found at https://www.mdpi.com/ 1422-0067/22/1/437/s1: Figure S1. Plant sterol biosynthetic pathway; Figure S2. DR5:GUS expression in shoot, root tips and lateral root primordia of 2-week-old WT and cpi1-1 seedlings; Figure S3. ProPIN1:GUS and ProPIN3:GUS expression in seedling shoots and roots; Figure S4. ProPIN4:GUS, ProPIN7:GUS and PIN7-GFP expression in WT and cpi1-1 roots and relative transcript levels of PIN genes; Figure S5. ProTIR2:GUS and ProTIR2:TIR2-GUS expression patterns in WT and cpi1-1 shoots; Figure S6. ProTAA1:GFP-TAA1 expression in 5-day-old WT and cpi1-1 seedling roots; Figure S7. ProYUC2:GUS, ProYUC3:GUS and ProYUC4:GUS expression patterns in 5-day-old seedlings; Figure S8. ProYUC8:GUS and ProYUC9:GUS expression patterns in 5-day-old WT and cpi1-1 seedling shoot, root vasculature, and root tip; Figure S9. ProASA1:GUS and ProASB1:GUS expression patterns in WT and cpi1-1 seedlings and relative transcript levels of auxin biosynthesis genes; Figure S10. Mutation of YUC2 or YUC3 does not rescue the short root and short hypocotyl phenotypes of cpi1-1; Figure S11. Relative transcript levels of auxin biosynthesis genes and polar auxin transport genes upon cycloeucalenol treatment; Figure S12. Relative transcript levels of auxin biosynthesis and polar auxin transport genes upon sitosterol treatment and ProTIR2:GUS and ProYUC9:GUS expression in seedling roots; Figure S13. Effects of stigmasterol and cholesterol on WT and cpi1-1 root growth. Table S1. List of primers used in this study.

Author Contributions: Data curation, M.W.; P.L.; Y.M.; X.N.; Formal analysis, M.W.; P.L.; Y.M.; X.N.; M.G.; S.M.; Funding acquisition, S.M.; Methodology, M.W.; P.L.; Y.M.; X.N.; Supervision, S.M.; Validation, M.W.; P.L.; Y.M.; X.N.; Writing—original draft, M.W.; S.M.; Writing—review \& editing, S.M.; M.G. All authors have read and agreed to the published version of the manuscript.

Funding: This work was supported by the National Natural Science Foundation of China (Grants $32,070,281,31,870,230,31,570,247$, and $91,417,308$ to S.M.).

Data Availability Statement: The data presented in this study are available in article and supplementary material.

Acknowledgments: We thank Nottingham Arabidopsis Stock Center (NASC) for providing mutant and transgene seeds. We thank Stephan Pollmann for the ProYUC8:GUS and ProYUC9:GUS seeds, Jiří Friml for DR5 rev:GFP and PIN7-GFP seeds, Mark Estelle for ProTIR2:GUS and ProTIR2:TIR2GUS seeds, Yunde Zhao for ProYUC2:GUS and ProYUC4:GUS seeds, Zhaojun Ding for yuc9, yuc9 $D R 5_{\text {rev }}: G F P$, and yuc8 yuc9 DR5 rev:GFP seeds.

Conflicts of Interest: The authors declare no conflict of interest. The founding sponsors had no role in the design of the study; in the collection, analyses, or interpretation of data; in the writing of the manuscript, and in the decision to publish the results. 


\begin{tabular}{|c|c|}
\hline \multicolumn{2}{|c|}{ Abbreviations } \\
\hline BRs & brassinosteroids \\
\hline fw & fresh weight \\
\hline IAA & indole-3-acetic acid \\
\hline Kyn & L-Kynurenine \\
\hline NPA & 1-N-naphthylphthalamic acid \\
\hline PAT & polar auxin transport \\
\hline PCIB & $p$-chlorophenoxyisobutyric acid \\
\hline QC & quiescent center \\
\hline SBIs & sterol biosynthetic intermediates \\
\hline WT & wild type \\
\hline
\end{tabular}

\section{References}

1. Mamode Cassim, A.; Gouguet, P.; Gronnier, J.; Laurent, N.; Germain, V.; Grison, M.; Boutté, Y.; Gerbeau-Pissot, P.; Simon-Plas, F.; Mongrand, S.; et al. Plant lipids: Key players of plasma membrane organization and function. Prog. Lipid Res. 2019, 73, 1-27. [CrossRef] [PubMed]

2. Grandmougin, A.; Bouvier-Navé, P.; Ullmann, P.; Benveniste, P.; Hartmann, M.A. Cyclopropyl sterol and phospholipid composition of membrane fractions from maize roots treated with fenpropimorph. Plant. Physiol. 1989, 90, 591-597. [CrossRef] [PubMed]

3. Benveniste, P. Biosynthesis and accumulation of sterols. Annu. Rev. Plant Biol. 2004, 55, 429-457. [CrossRef] [PubMed]

4. Schaller, H. New aspects of sterol biosynthesis in growth and development of higher plants. Plant Physiol. Biochem. 2004, 42, 465-476. [CrossRef] [PubMed]

5. Moreau, R.; Nyström, L.; Whitaker, B.D.; Winkler-Moser, J.K.; Baer, D.J.; Gebauer, S.K.; Hicks, K.B. Phytosterols and their derivatives: Structural diversity, distribution, metabolism, analysis, and health-promoting uses. Prog. Lipid Res. 2018, $70,35-61$. [CrossRef] [PubMed]

6. Guo, D.-A.; Venkatramesh, M.; Nes, W.D. Developmental regulation of sterol biosynthesis inZea mays. Lipids 1995, 30, 203-219. [CrossRef]

7. Schaeffer, A.; Bronner, R.; Benveniste, P.; Schaller, H. The ratio of campesterol to sitosterol that modulates growth in Ara-bidopsis is controlled by STEROL METHYLTRANSFERASE2; 1. Plant. J. 2001, 25, 605-615. [CrossRef]

8. Men, S.; Boutté, Y.; Ikeda, Y.; Li, X.; Palme, K.; Stierhof, Y.D.; Hartmann, M.A.; Moritz, T.; Grebe, M. Sterol-dependent en-docytosis mediates post-cytokinetic acquisition of PIN2 auxin efflux carrier polarity. Nat. Cell Biol. 2008, 10, 237-244. [CrossRef]

9. Carland, F.; Fujioka, S.; Nelson, T. The Sterol Methyltransferases SMT1, SMT2, and SMT3 Influence Arabidopsis Development through Nonbrassinosteroid Products. Plant Physiol. 2010, 153, 741-756. [CrossRef]

10. Mialoundama, A.S.; Jadid, N.; Brunel, J.; Di Pascoli, T.; Heintz, D.; Erhardt, M.; Mutterer, J.; Bergdoll, M.; Ayoub, D.; Van Dorsselaer, A.; et al. Arabidopsis ERG28 Tethers the Sterol C4-Demethylation Complex to Prevent Accumulation of a Biosynthetic Intermediate That Interferes with Polar Auxin Transport. Plant Cell 2013, 25, 4879-4893. [CrossRef]

11. Klahre, U.; Noguchi, T.; Fujioka, S.; Takatsuto, S.; Yokota, T.; Nomura, T.; Yoshida, S.; Chua, N.H. The Arabidopsis DIMINUTO/DWARF1 gene encodes a protein involved in steroid synthesis. Plant Cell 1998, 10, 1677-1690. [PubMed]

12. Choe, S.; Noguchi, T.; Fujioka, S.; Takatsuto, S.; Tissier, C.P.; Gregory, B.D.; Ross, A.S.; Tanaka, A.; Yoshida, S.; Tax, F.E.; et al. The Arabidopsis dwf7/ste1 mutant is defective in the $\Delta 7$ sterol C-5 desaturation step leading to brassinosteroid biosynthesis. Plant Cell 1999, 11, 207-221. [PubMed]

13. Choe, S.; Dilkes, B.P.; Gregory, B.D.; Ross, A.S.; Yuan, H.; Noguchi, T.; Fujioka, S.; Takatsuto, S.; Tanaka, A.; Yoshida, S.; et al. The Arabidopsis dwarf1 mutant is defective in the conversion of 24-methylenecholesterol to campesterol in brasssinosteroid biosynthesis. Plant Physiol. 1999, 119, 897-907. [CrossRef] [PubMed]

14. Wei, Z.; Li, J. Regulation of Brassinosteroid Homeostasis in Higher Plants. Front. Plant Sci. 2020, 11, 583622. [CrossRef]

15. Topping, J.F.; May, V.J.; Musket, P.R.; Lindsey, K. Mutations in the HYDRA1 gene of Arabidopsis perturb cell shape and dis-rupt embryonic and seedling morphogenesis. Development 1997, 124, 4415-4424.

16. Diener, A.C.; Li, H.; Zhou, W.; Whoriskey, W.J.; Nes, W.D.; Fink, G.R. Sterol methyltransferase 1 controls the level of choles-terol in plants. Plant Cell 2000, 12, 853-870.

17. Jang, J.-C.; Fujioka, S.; Tasaka, M.; Seto, H.; Takatsuto, S.; Ishii, A.; Aida, M.; Yoshida, S.; Sheen, J. A critical role of sterols in embryonic patterning and meristem programming revealed by the fackel mutants of Arabidopsis thaliana. Genes Dev. 2000, 14, 1485-1497.

18. Schrick, K.; Mayer, U.; Horrichs, A.; Kuhnt, C.; Bellini, C.; Dangl, J.; Schmidt, J.; Jürgens, G. FACKEL is a sterol C-14 reduc-tase required for organized cell division and expansion in Arabidopsis embryogenesis. Genes Dev. 2000, 14, 1471-1484.

19. Willemsen, V.; Friml, J.; Grebe, M.; van den Toorn, A.; Palme, K.; Scheres, B. Cell polarity and PIN protein positioning in Ar-abidopsis require STEROL METHYLTRANSFERASE1 function. Plant Cell 2003, 15, 612-625. [CrossRef]

20. Kim, H.B.; Schaller, H.; Goh, C.-H.; Kwon, M.; Choe, S.; An, C.S.; Durst, F.; Feldmann, K.A.; Feyereisen, R. Arabidopsis cyp51 Mutant Shows Postembryonic Seedling Lethality Associated with Lack of Membrane Integrity. Plant Physiol. 2005, 138, $2033-2047$. [CrossRef] 
21. Zhang, X.; Sun, S.; Nie, X.; Boutté, Y.; Grison, M.; Shuangli, S.; Kuang, S.; Men, S. Sterol Methyl Oxidases Affect Embryo Development via Auxin-Associated Mechanisms. Plant Physiol. 2016, 171, 468-482. [CrossRef] [PubMed]

22. Song, J.; Sun, S.; Ren, H.; Grison, M.; Boutté, Y.; Bai, W.; Men, S. The SMO1 Family of Sterol $4 \alpha$-Methyl Oxidases Is Essential for Auxin- and Cytokinin-Regulated Embryogenesis. Plant Physiol. 2019, 181, 578-594. [CrossRef] [PubMed]

23. Souter, M.; Topping, J.; Pullen, M.; Friml, J.; Palme, K.; Hackett, R.; Grierson, D.; Lindsey, K. hydra Mutants of Arabidopsis Are Defective in Sterol Profiles and Auxin and Ethylene Signaling. Plant Cell 2002, 14, 1017-1031. [CrossRef] [PubMed]

24. Pan, J.; Fujioka, S.; Peng, J.; Chen, J.; Li, G.; Chen, R. The E3 Ubiquitin Ligase SCFTIR1/AFB and Membrane Sterols Play Key Roles in Auxin Regulation of Endocytosis, Recycling, and Plasma Membrane Accumulation of the Auxin Efflux Transporter PIN2 in Arabidopsis thaliana. Plant Cell 2009, 21, 568-580. [CrossRef] [PubMed]

25. Pullen, M.; Clark, N.; Zarinkamar, F.; Topping, J.; Lindsey, K. Analysis of vascular development in the hydra sterol biosyn-thetic mutants of Arabidopsis. PLoS ONE 2010, 5, el2227. [CrossRef]

26. Nakamoto, M.; Schmit, A.-C.; Heintz, D.; Schaller, H.; Ohta, D. Diversification of sterol methyltransferase enzymes in plants and a role for $\beta$-sitosterol in oriented cell plate formation and polarized growth. Plant J. 2015, 84, 860-874. [CrossRef] [PubMed]

27. Short, E.; Leighton, M.; Imriz, G.; Liu, D.; Cope-Selby, N.; Hetherington, F.; Smertenko, A.; Hussey, P.J.; Topping, J.F.; Lind-sey, K. Epidermal expression of a sterol biosynthesis gene regulates root growth by a non-cell-autonomous mechanism in Ara-bidopsis. Development 2018, 145, dev160572. [CrossRef]

28. Grebe, M.; Xu, J.; Möbius, W.; Ueda, T.; Nakano, A.; Geuze, H.J.; Rook, M.B.; Scheres, B. Arabidopsis sterol endocytosis in-volves actin-mediated trafficking via ARA6-positive early endosomes. Curr. Biol. 2003, 13, 1378-1387. [CrossRef]

29. Rahier, A.; Taton, M.; Benveniste, P. Cycloeucalenol—obtusifoliol isomerase. Structural requirements for transformation or binding of substrates and inhibitors. JBIC J. Biol. Inorg. Chem. 1989, 181, 615-626. [CrossRef]

30. Lovato, M.A.; Hart, E.A.; Segura, M.J.; Giner, J.L.; Matsuda, S.P. Functional cloning of an Arabidopsis thaliana cDNA encoding cycloeucalenol cycloisomerase. J. Biol. Chem. 2000, 275, 13394-13397. [CrossRef]

31. Qian, P.; Han, B.; Forestier, E.; Hu, Z.; Gao, N.; Lu, W.; Schaller, H.; Li, J.; Hou, S. Sterols are required for cell-fate commit-ment and maintenance of the stomatal lineage in Arabidopsis. Plant J. 2013, 74, 1029-1044. [CrossRef] [PubMed]

32. Ulmasov, T.; Murfett, J.; Hagen, G.; Guilfoyle, T.J. AUX/IAA proteins repress expression of reporter genes containing natural and highly active synthetic auxin response elements. Plant Cell 1997, 9, 1963-1971. [PubMed]

33. Sabatini, S.; Beis, D.; Wolkenfelt, H.; Murfett, J.; Guilfoyle, T.; Malamy, J.; Benfey, P.; Leyser, O.; Bechtold, N.; Weisbeek, P.; et al. An Auxin-Dependent Distal Organizer of Pattern and Polarity in the Arabidopsis Root. Cell 1999, 99, 463-472. [CrossRef]

34. Fischer, U.; Ikeda, Y.; Ljung, K.; Serralbo, O.; Singh, M.; Heidstra, R.; Palme, K.; Scheres, B.; Grebe, M. Vectorial Information for Arabidopsis Planar Polarity Is Mediated by Combined AUX1, EIN2, and GNOM Activity. Curr. Biol. 2006, 16, $2143-2149$. [CrossRef]

35. Ikeda, Y.; Men, S.; Fischer, U.; Stepanova, A.N.; Alonso, J.M.; Ljung, K.; Grebe, M. Local auxin biosynthesis modulates gradi-entdirected planar polarity in Arabidopsis. Nat. Cell Biol. 2009, 11, 731-738. [CrossRef]

36. Liu, H.; Liu, B.; Chen, X.; Zhu, H.; Zou, C.; Men, S. AUX1 acts upstream of PIN2 in regulating root gravitropism. Biochem. Biophys. Res. Commun. 2018, 507, 433-436. [CrossRef]

37. Ljung, K. Auxin metabolism and homeostasis during plant development. Development 2013, 140, 943-950. [CrossRef]

38. Stepanova, A.N.; Robertson-Hoyt, J.; Yun, J.; Benavente, L.M.; Xie, D.-Y.; Doležal, K.; Schlereth, A.; Jürgens, G.; Alonso, J.M. TAA1-Mediated Auxin Biosynthesis Is Essential for Hormone Crosstalk and Plant Development. Cell 2008, 133, 177-191. [CrossRef]

39. Tao, Y.; Ferrer, J.-L.; Ljung, K.; Pojer, F.; Hong, F.; Long, J.A.; Li, L.; Moreno, J.E.; Bowman, M.E.; Ivans, L.J.; et al. Rapid Synthesis of Auxin via a New Tryptophan-Dependent Pathway Is Required for Shade Avoidance in Plants. Cell 2008, 133, 164-176. [CrossRef]

40. Yamada, M.; Greenham, K.; Prigge, M.J.; Jensen, P.J.; Estelle, M. The TRANSPORT INHIBITOR RESPONSE2 Gene Is Required for Auxin Synthesis and Diverse Aspects of Plant Development. Plant Physiol. 2009, 151, 168-179. [CrossRef]

41. Brumos, J.; Robles, L.M.; Yun, J.; Vu, T.C.; Jackson, S.; Alonso, J.M.; Stepanova, A.N. Local auxin biosynthesis is a key regu-lator of plant development. Dev. Cell 2018, 47, 306-318. [CrossRef] [PubMed]

42. Mashiguchi, K.; Tanaka, K.; Sakai, T.; Sugawara, S.; Kawaide, H.; Natsume, M.; Hanada, A.; Yaeno, T.; Shirasu, K.; Yao, H.; et al. The main auxin biosynthesis pathway in Arabidopsis. Proc. Natl. Acad. Sci. USA 2011, 108, 18512-18517. [CrossRef]

43. Stepanova, A.N.; Yun, J.; Robles, L.M.; Novak, O.; He, W.; Guo, H.; Ljung, K.; Alonso, J.M. The Arabidopsis YUCCA1 Flavin Monooxygenase Functions in the Indole-3-Pyruvic Acid Branch of Auxin Biosynthesis. Plant Cell 2011, 23, 3961-3973. [CrossRef] [PubMed]

44. Won, C.; Shen, X.; Mashiguchi, K.; Zheng, Z.; Dai, X.; Cheng, Y.; Kasahara, H.; Kamiya, Y.; Chory, J.; Zhao, Y. Conversion of tryptophan to indole-3-acetic acid by tryptophan aminotransferases of arabidopsis and YUCCAs in Ara-bidopsis. Proc. Natl. Acad. Sci. USA 2011, 108, 18518-18523. [CrossRef] [PubMed]

45. Cheng, Y.; Dai, X.; Zhao, Y. Auxin biosynthesis by the YUCCA flavin monooxygenases controls the formation of floral organs and vascular tissues inArabidopsis. Genes Dev. 2006, 20, 1790-1799. [CrossRef]

46. Hentrich, M.; Böttcher, C.; Düchting, P.; Cheng, Y.; Zhao, Y.; Berkowitz, O.; Masle, J.; Medina, J.; Pollmann, S. The jasmonic acid signaling pathway is linked to auxin homeostasis through the modulation of YUCCA8andYUCCA9gene expression. Plant $J$. 2013, 74, 626-637. [CrossRef] [PubMed] 
47. Stepanova, A.N.; Hoyt, J.M.; Hamilton, A.A.; Alonso, J.M. A link between ethylene and auxin uncovered by the characteri-zation of two root-specific ethylene-insensitive mutants in Arabidopsis. Plant Cell 2005, 17, 2230-2242. [CrossRef] [PubMed]

48. He, W.; Brumos, J.; Li, H.; Ji, Y.; Ke, M.; Gong, X.; Zeng, Q.; Li, W.; Zhang, X.; An, F.; et al. A Small-Molecule Screen Identifies 1-Kynurenine as a Competitive Inhibitor of TAA1/TAR Activity in Ethylene-Directed Auxin Biosynthesis and Root Growth in Arabidopsis. Plant Cell 2011, 23, 3944-3960. [CrossRef]

49. Oono, Y.; Ooura, C.; Rahman, A.; Aspuria, E.T.; Hayashi, K.; Tanaka, A.; Uchimiya, H. p-Chlorophenoxyisobutyric acid im-pairs auxin response in Arabidopsis root. Plant Physiol. 2003, 133, 1135-1147. [CrossRef]

50. Zhao, H.; Ma, B.; Duan, K.-X.; Li, X.-K.; Lu, X.; Yin, C.-C.; Tao, J.-J.; Wei, W.; Zhang, W.; Xin, P.-Y.; et al. The GDSL Lipase MHZ11 Modulates Ethylene Signaling in Rice Roots. Plant Cell 2020, 32, 1626-1643. [CrossRef]

51. Swarup, R.; Perry, P.; Hagenbeek, D.; Van Der Straeten, D.; Beemster, G.T.; Sandberg, G.; Bhalerao, R.; Ljung, K.; Bennett, M.J. Ethylene Upregulates Auxin Biosynthesis in Arabidopsis Seedlings to Enhance Inhibition of Root Cell Elongation. Plant Cell 2007, 19, 2186-2196. [CrossRef]

52. Růžička, K.; Ljung, K.; Vanneste, S.; Podhorská, R.; Beeckman, T.; Friml, J.; Benková, E. Ethylene Regulates Root Growth through Effects on Auxin Biosynthesis and Transport-Dependent Auxin Distribution. Plant Cell 2007, 19, 2197-2212. [CrossRef] [PubMed]

53. Stepanova, A.N.; Yun, J.; Likhacheva, A.V.; Alonso, J.M. Multilevel Interactions between Ethylene and Auxin in Arabidopsis Roots. Plant Cell 2007, 19, 2169-2185. [CrossRef] [PubMed]

54. Yang, Z.-B.; Geng, X.; He, C.; Zhang, F.; Wang, R.; Horst, W.J.; Ding, Z. TAA1-Regulated Local Auxin Biosynthesis in the RootApex Transition Zone Mediates the Aluminum-Induced Inhibition of Root Growth in Arabidopsis. Plant Cell 2014, 26, 2889-2904. [CrossRef] [PubMed]

55. Babiychuk, E.; Bouvier-Navé, P.; Compagnon, V.; Suzuki, M.; Muranaka, T.; Van Montagu, M.; Kushnir, S.; Schaller, H. Al-lelic mutant series reveal distinct functions for Arabidopsis cycloartenol synthase1 in cell viability and plastid biogenesis. Proc. Natl. Acad. Sci. USA 2008, 105, 3163-3168. [CrossRef]

56. Ohyama, K.; Suzuki, M.; Kikuchi, J.; Saito, K.; Muranaka, T. Dual biosynthetic pathways to phytosterol via cycloartenol and lanosterol in Arabidopsis. Proc. Natl. Acad. Sci. USA 2009, 106, 725-730. [CrossRef]

57. Sonawane, P.D.; Pollier, J.; Panda, S.; Szymanski, J.; Massalha, H.; Yona, M.; Unger, T.; Malitsky, S.; Arendt, P.; Pauwels, L.; et al. Plant cholesterol biosynthetic pathway overlaps with phytosterol metabolism. Nat. Plants 2016, 3, 16205. [CrossRef]

58. Villette, C.; Berna, A.; Compagnon, V.; Schaller, H. Plant Sterol Diversity in Pollen from Angiosperms. Lipids 2015, 50, 749-760. [CrossRef]

59. Rotsch, A.H.; Kopka, J.; Feussner, I.; Ischebeck, T. Central metabolite and sterol profiling divides tobacco male gametophyte development and pollen tube growth into eight metabolic phases. Plant J. 2017, 92, 129-146. [CrossRef]

60. Suzuki, M.; Kamide, Y.; Nagata, N.; Seki, H.; Ohyama, K.; Kato, H.; Masuda, K.; Sato, S.; Kato, T.; Tabata, S.; et al. Loss of function of 3-hydroxy-3-methylglutaryl coenzyme A reductase 1 (HMG1) in Arabidopsis leads to dwarfing, early senescence and male sterility, and reduced sterol levels. Plant J. 2004, 37, 750-761. [CrossRef]

61. He, J.-X.; Fujioka, S.; Li, T.-C.; Kang, S.G.; Seto, H.; Takatsuto, S.; Yoshida, S.; Jang, J.-C. Sterols Regulate Development and Gene Expression in Arabidopsis. Plant Physiol. 2003, 131, 1258-1269. [CrossRef] [PubMed]

62. Porter, J.A.; Young, K.E.; Beachy, P.A. Cholesterol Modification of Hedgehog Signaling Proteins in Animal Development. Science 1996, 274, 255-259. [CrossRef] [PubMed]

63. Gallet, A.; Ruel, L.; Staccini-Lavenant, L.; Thérond, P.P. Cholesterol modification is necessary for controlled planar long-range activity of Hedgehog in Drosophila epithelia. Development 2006, 133, 407-418. [CrossRef] [PubMed]

64. Xiao, X.; Tang, J.-J.; Peng, C.; Wang, Y.; Fu, L.; Qiu, Z.-P.; Xiong, Y.; Yang, L.-F.; Cui, H.-W.; He, X.-L.; et al. Cholesterol Modification of Smoothened Is Required for Hedgehog Signaling. Mol. Cell 2017, 66, 154-162.e10. [CrossRef] [PubMed]

65. Dalal, J.; Lewis, D.R.; Tietz, O.; Brown, E.M.; Brown, C.S.; Palme, K.; Muday, G.K.; Sederoff, R.R. ROSY1, a novel regulator of gravitropic response is a stigmasterol binding protein. J. Plant Physiol. 2016, 196, 28-40. [CrossRef]

66. Frescatada-Rosa, M.; Stanislas, T.; Backues, S.K.; Reichardt, I.; Men, S.; Boutté, Y.; Jürgens, G.; Moritz, T.; Bednarek, S.Y.; Grebe, M. High lipid order of Arabidopsis cell-plate membranes mediated by sterol and dynamin-related protein1a function. Plant $J$. 2014, 80, 745-757. [CrossRef]

67. Robert, H.S.; Grones, P.; Stepanova, A.N.; Robles, L.; Lokerse, A.S.; Alonso, J.M.; Weijers, D.; Friml, J. Local Auxin Sources Orient the Apical-Basal Axis in Arabidopsis Embryos. Curr. Biol. 2013, 23, 2506-2512. [CrossRef]

68. Liu, G.; Gao, S.; Tian, H.; Wu, W.; Robert, H.S.; Ding, Z. Local Transcriptional Control of YUCCA Regulates Auxin Promoted Root-Growth Inhibition in Response to Aluminium Stress in Arabidopsis. PLoS Genet. 2016, 12, e1006360. [CrossRef]

69. Friml, J.; Vieten, A.; Sauer, M.; Weijers, D.; Schwarz, H.; Hamann, T.; Offringa, R.; Jürgens, G. Efflux-dependent auxin gra-dients establish the apical-basal axis of Arabidopsis. Nature 2003, 426, 147-153. [CrossRef]

70. Benková, E.; Michniewicz, M.; Sauer, M.; Teichmann, T.; Seifertová, D.; Jürgens, G.; Friml, J. Local, Efflux-Dependent Auxin Gradients as a Common Module for Plant Organ Formation. Cell 2003, 115, 591-602. [CrossRef]

71. Friml, J.; Wiśniewska, J.; Benková, E.; Mendgen, K.; Palme, K. Lateral relocation of auxin efflux regulator PIN3 mediates tro-pism in Arabidopsis. Nature 2002, 415, 806-809. [CrossRef] [PubMed] 
72. Friml, J.; Benková, E.; Blilou, I.; Wisniewska, J.; Hamann, T.; Ljung, K.; Woody, S.; Sandberg, G.; Scheres, B.; Jürgens, G.; et al. AtPIN4 Mediates Sink-Driven Auxin Gradients and Root Patterning in Arabidopsis. Cell 2002, 108, 661-673. [CrossRef]

73. Blilou, I.; Xu, J.; Wildwater, M.; Willemsen, V.; Paponov, I.; Friml, J.; Heidstra, R.; Aida, M.; Palme, K.; Scheres, B. The PIN auxin efflux facilitator network controls growth and patterning in Arabidopsis roots. Nature 2005, 433, 39-44. [CrossRef] [PubMed] 